\title{
A coordinate-based meta-analysis of white matter alterations in patients with alcohol use
}

disorder

Carolin Spindler (M.Sc.) $)^{1}$, Louisa Mallien (M.Sc.) ${ }^{2}$, Sebastian Trautmann (Ph.D.) ${ }^{1}$, Nina Alexander (Ph.D.) $)^{1}$, Markus Muehlhan (Ph.D. $)^{1 *}$.

1Department of Psychology, Faculty of Human Sciences, Medical School Hamburg, Am Kaiserkai 1, 20457 Hamburg, Germany

${ }^{2}$ Department of Human Medicine, Faculty of Medicine, Medical School Hamburg, Am Kaiserkai 1, 20457 Hamburg, Germany

\section{${ }^{*}$ Corresponding author:}

Markus Muehlhan, Prof. Dr. rer. nat. (Ph.D.)

Department of Psychology

Faculty of Human Science

Medical School Hamburg MSH

Am Kaiserkai 1

D-20457 Hamburg, Germany

Phone: +494036122649324

Fax: $\quad+4940361226430$

E-Mail: markus.muehlhan@medicalschool-hamburg.de

Running Title: White matter alterations in Alcohol Use Disorder

\section{Open Access online publication:}

Spindler, C., Mallien, L., Trautmann, S., Alexander, N. \& Muehlhan, M. (2022). A coordinate-based meta-analysis of white matter alterations in patients with alcohol use disorder. Transl Psychiatry 12 (1), 40. https://doi.org/10.1038/s41398-022-01809-0 


\begin{abstract}
Introduction: Besides the commonly described grey matter (GM) deficits, there is growing evidence of significant white matter (WM) alterations in patients with alcohol use disorder (AUD). WM changes can be assessed using volumetric and diffusive magnetic resonance imaging methods, such as voxel-based morphometry (VBM) and diffusion tensor imaging (DTI). The aim of the present meta-analysis is to investigate the spatial convergence of the reported findings on WM alterations in AUD. Methods: Systematic literature search on PubMed and further databases revealed 18 studies eligible for inclusion, entailing a total of 462 AUD patients and 416 healthy controls (up to January 18, 2021). All studies that had used either VBM or DTI whole-brain analyzing methods and reported results as peak-coordinates in standard reference space were considered for inclusion. We excluded studies using approaches nonconcordant with recent guidelines for neuroimaging meta-analyses and studies investigating patient groups with Korsakoff syndrome or other comorbid substance use disorders (except tobacco). Results: Anatomical Likelihood Estimation (ALE) revealed four significant clusters of convergent macro- and microstructural WM alterations in AUD patients that were assigned to the genu and body of the corpus callosum, anterior and posterior cingulum, fornix, and the right posterior limb of the internal capsule. Discussion: The changes in WM could to some extent explain the deteriorations in motor, cognitive, affective, and perceptual functions seen in AUD. Future studies are needed to clarify how WM alterations vary over the course of the disorder and to what extent they are reversible with prolonged abstinence.
\end{abstract}




\section{Introduction}

Alcohol Use Disorder (AUD) is highly prevalent worldwide, leads to extensive health and economic burdens and represents a leading cause of preventable deaths ${ }^{1,2}$.

Heavy chronic alcohol consumption causes numerous somatic diseases (e.g. liver disease, cancer) ) $^{3,4}$ and poses damage of the central nervous system $(\mathrm{CNS})^{5,6}$. As a consequence, impaired cognitive functioning and, in severe cases, alcohol-related dementia have been frequently described in AUD patients ${ }^{7}$. Several processes might account for neurodegeneration in AUD, such as the toxic effects of ethanol and its metabolites itself as well as the frequent co-existing nutritional or vitamin deficiencies ${ }^{8}$. Moreover, dysregulations of central stress response systems due to chronic alcohol consumption and inflammatory mechanisms are also discussed as potential causes of CNS damages in AUD ${ }^{9-11}$.

Specifically, these multiple factors can lead to injuries of neurons as well as glial cells of all types and induce demyelination and axonal damage, depending on dose and duration of exposure ${ }^{9,12}$. Furthermore, age, sex as well as comorbid neurological and psychological conditions are discussed as potential moderators in this context 7,13 . Intriguingly, some of these structural damages might be partially reversible with prolonged abstinence $\left({ }^{14}\right.$, see ${ }^{7-11,15}$ for review).

Structural brain alterations in AUD have been investigated in a large number of neuroimaging studies. Regarding GM changes, several meta-analyses highlighted specific patterns of reduced regional brain volume or density ${ }^{16-18}$. In recent years, the number of studies investigating the macro- and microstructure of WM by magnetic resonance imaging (MRI) methods has also increased. These studies showed WM changes in numerous locations of different fiber tracts (e. g. ${ }^{19-22}$ and ${ }^{23,24}$ for review). A first meta-analysis by Monnig and colleagues ${ }^{25}$ revealed significant WM volumetric reductions in AUD relative to healthy comparison groups. This important work showed small to moderate effect sizes ( $g=$ $.304, S D=0.134)$ but did not test for convergence of imaging results in order to draw conclusions about the location of altered WM in AUD. A recent large-scale meta-analysis focused on gray and white matter morphology across all substance use disorders and indicates general and substance-specific structural brain changes in patients compared with healthy controls ${ }^{26}$. Sub-analysis regarding AUD in specific revealed convergent WM alterations in regions of the corticospinal tract and anterior thalamic radiation. However, these findings refer to the macrostructural results of only five voxel-based morphometry (VBM) studies and should be interpreted with great caution due to the low statistical power ${ }^{27}$. 
To date, a coordinate-based meta-analysis specifically focusing on the localization of WM alterations in AUD with sufficient power to generate robust results is still lacking ${ }^{27,28}$. Our work aims to fill this gap by combining volumetric and diffusion-based MRI results of prior studies.

Besides the voxel-by-voxel volumetric comparisons, as it is done in VBM methods ${ }^{29,30}$, diffusion tensor Imaging (DTI) can be used to determine the directionality of the diffusion of hydrogen protons, which is assumed to provide information about the microstructural integrity of the fiber tracts ${ }^{31,32}$. Although volumetric and diffusion-based methods measure different features of WM, both provide information on WM changes in patient groups compared to healthy controls and meta-analytically integrating results of studies applying one of both methods can give a more comprehensive overview of the affected brain regions (e. g. $\left.{ }^{33}\right)$.

To identify VBM and DTI studies on WM macro- and microstructural changes in AUD, we first conducted a systematic literature review in accordance with the Preferred Reporting Items for Systematic reviews and Meta-Analyses (PRISMA) ${ }^{34}$. The reported spatial coordinates of each study were extracted, weighted, and tested for spatial convergence using Anatomical Likelihood Estimation (ALE). This method allows quantitative and unbiased integration of neuroimaging findings. Current guidelines for quantitative coordinate-based meta-analyses ${ }^{27,28}$ were meticulously followed in all steps of the work. 


\section{Methods}

Details of the protocol for this meta-analysis were registered on PROSPERO and can be assessed at https://www.crd.york.ac.uk/prospero/display record.php?ID=CRD42021231447/display record.php?ID $=$ CRD42021231447.

\subsection{Literature search, study selection and data extraction}

The search for neuroimaging studies investigating WM alterations in patients with AUD compared to healthy controls was conducted up to January 18, 2021, on PubMed and on EBSCO hosted PsycINFO, PsycARTICLES, MEDLINE Complete, CINAHL Complete and Psychology and Behavioral Sciences Collection databases were used as well as reference-tracing of the retrieved articles. Database filters were set for: Humans, English, Peer-Reviewed.

Keywords were: (alcohol misuse OR alcoholism OR alcohol drinking OR drinking behavior OR binge drinking OR alcoholics OR alcohol use disorder OR alcohol dependence OR alcohol addiction OR chronic alcoholic intoxication OR alcohol abuse) AND (white matter OR white brain matter OR cerebellar white matter OR white matter integrity) AND (diffusion tensor* OR DTI OR magnetic resonance imaging OR tractography OR mean diffusivity OR axial diffusivity OR radial diffusivity OR fractional anisotropy OR structural connectivity OR structural changes OR structural MRI OR voxel-based morphometry OR VBM).

Study inclusion criteria comprised (1) written in English language and peer-reviewed, (2) contains a statistical comparison of WM by means of VBM or DTI in the whole brain, (3) compares adult patients diagnosed with AUD (DSM-IV, DSM-5 or ICD-10) with healthy controls. AUD (as specified in DSM-5) is referred to as a disorder continuum subsuming DSM-IV diagnosis of alcohol abuse and alcohol dependence as well as ICD-10 diagnosis of harmful alcohol use and alcohol dependence. (4) Results were reported as 3-D coordinates in a standard reference space.

For exclusion, the following criteria were defined: (1) review-studies, meta-analyses, and re-analyses, (2) region of interest analyses, small volume corrected results and investigations with only partial brain coverage, (3) methodological studies and study protocols, (4) studies with small sample sizes (<10 per group) and (5) studies with statistical approaches not correcting for multiple comparisons or setting a minimum cluster extension as statistical threshold for significance. Unlike conventional meta-analytical methods, (6) studies reporting null-findings could not be taken into account because they do not provide spatial coordinates, which are a prerequisite for coordinate based meta-analyses. (7) Studies 
investigating patient groups with Korsakoff syndrome, with other primary psychopathology or comorbid other substance use disorder (except for tobacco).

Study selection and data extraction were performed independently by two investigators (C. S. and L. M.). Disagreements were solved by consensus with help of the supervising researcher (M. M.). The data extraction from the eligible studies included demographic sample characteristics and methodological characteristics as well as the resulting peak voxel coordinates. In addition, all studies were carefully checked for possible sample overlap. This step was also double checked by C.S. and L.M. Where data was missing or inconclusive in the original publications, we reached out to the corresponding authors to inquire the supplementary information needed. In a few cases we kindly received fast and helpful feedback (see Acknowledgements). Unfortunately, most of the contacted authors did not respond to our requests and therefore, studies with missing necessary supplemental information were excluded.

Quality assessment was carried out in accordance with recommendations for analysis and reporting in neuroimaging ${ }^{35}$ and guidelines for neuroimaging meta-analyses ${ }^{27,28}$. Each included study was checked for a number of quality criteria such as sample and control group characteristics, information on MRI acquisition and statistical analysis.

Potential publication bias and robustness of results were estimated by applying a modified version of the Fail-Safe $\mathrm{N}$ method $(\mathrm{FSN})^{36}$.

\subsection{Anatomical Likelihood Estimation}

The meta-analytical approach of Anatomical Likelihood Estimation follows the principles of Activation Likelihood Estimation (ALE) 37,38 , whereby the above-chance convergence among the reported coordinates of the individual studies gets detected.

For preparation of the synthesis, the reported peak voxel coordinates and the sample sizes of the individual studies were manually extracted into a text-file and served as input data for performing an ALE meta-analysis. In one case, where the peak voxel coordinates were not published and we requested them via personal correspondence, we received an NIftl output file created by FMRIB Software Library (FSL) ${ }^{39}$ randomise tool (https://fsl.fmrib.ox.ac.uk/fsl/fslwiki/Randomise). For extraction of the most meaningful peak voxels, we used FSL v6.0 (https://fsl.fmrib.ox.ac.uk/fsl/fslwiki/FSL) on Windows 10 and the cluster tool (https://fsl.fmrib.ox.ac.uk/fsl/fslwiki/Cluster), setting the threshold for the cluster level to $p<0.01$. In three other studies where the coordinates were specified in Talairach space, we used the Lancaster icbm2tal transform implemented in GingerALE v3.0.2 to transform to MNI space (http://www.brainmap.org/ale/) ${ }^{40,41}$. The same version of GingerALE was used to perform the 
meta-analysis itself $\mathrm{f}^{37,38,42}$. Prior to the actual meta-analytical calculations, four mask outliers were identified in the input data and were subjected to a plausibility check. In one case, for a coordinate reported from Yeh et al. ${ }^{43}$ (Table 1: $x=28, y=52, z=51$ ), we suspected a missing negative sign. According to the anatomical label in the original publication, the sign of the $y$-coordinate was set to (-) as recommended in the User Manual for GingerALE 2.3 (https://brainmap.org/ale). Now the coordinate reads $x=28, y=-52, z=51$. Another outlier was located a few millimeters next to the brainstem, which could be caused by the transformation processes (Crespi et al. ${ }^{44}$, suppl. Table S3: $x=-6, y=-9, z=-24$ ). This coordinate, as well as the other two mask outliers (Harris et al. ${ }^{45}$, Table $3: x=15, y=46, z=-55$ and $x=-44, y=18, z=-53)$, remained in the data set, because we could not clarify the exact position. The overall number of mask outliers was below the critical limit of 3\% (see User Manual for GingerALE 2.3, https://brainmap.org/ale/). No sample overlap was identified within the studies eligible for inclusion and therefore data from each study was managed independently in the analysis. We combined the results from all contrasts ( $A U D<H C$ and $A U D>H C$ ), since ALE is testing independently from the direction of the effects $^{28}$. If a sufficiently large number of individual studies was identified that used either DTI or VBM methods, appropriate subgroup analyses were performed in the course of the analysis.

After preparing the input file, we set GingerALE's thresholding options to cluster level family wise error correction (cFWE) with $p<0.001$ as the cluster-forming threshold and $p<0.05$ as the FWE threshold. This procedure ensures low susceptibility to false positive results ${ }^{28,46}$. We furthermore set preferences for inclusion of WM in labelling the cluster analysis results.

The ALE procedure follows three steps, which we will only briefly describe here (see $37,38,42$ for detailed information). First, GingerALE tests for the spatial uncertainty of the reported coordinates by modelling them with a Gaussian function, thereby accounting for the sample size of each study. This is followed by the construction of a whole brain map for each study, whereby each voxel gets a value assigned that is equal to the probability of WM volume or integrity alterations within it. Subsequently, these maps are merged across all studies resulting in an ALE image with ALE values representing the likelihood of these alterations and tested for statistical significance with correction for multiple comparisons.

Finally, the measure of effect represents an ALE image with ALE values that in turn indicates the likelihood that structural differences were found at least for one study at a given voxel. Outcome variables are MNI peak voxel coordinates of the resulting clusters of convergence as well as information on cluster sizes $\left(\mathrm{mm}^{3}\right)$, cluster labels and name and number of contributing studies. 


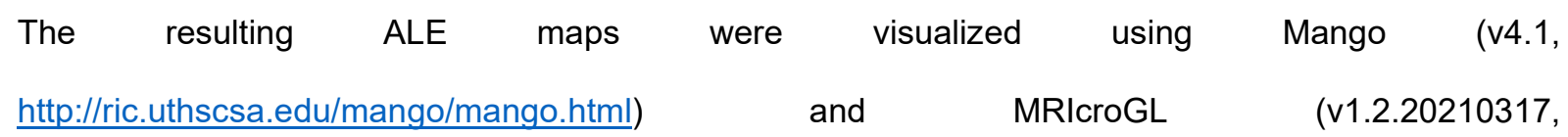
https://www.mccauslandcenter.sc.edu/mricrogl/).

\subsection{Assignment to human brain white matter atlas}

Since the Talairach and Tournoux atlas ${ }^{47}$, which is implemented in GingerALE, does not provide differentiated WM references ${ }^{48}$, we decided to use an additional tractography based atlas of human brain connections ${ }^{49}$, implemented in MRIcroGL (v1.2.20210317, https://www.mccauslandcenter.sc.edu/mricrogl/), for labelling.

\section{Results}

\subsection{Eligibility of Studies}

Systematic literature search revealed 18 studies eligible for inclusion ${ }^{13,14,19,20,43-45,50-60}$, entailing a total of 462 AUD patients and 416 healthy controls. The flow of information through the different phases of the review is depicted in Figure 1. The main reason for exclusion refers to investigations of WM in AUD with other measures than DTI or VBM, for example connectivity analysis (e. g. ${ }^{61}$ ) or WM signal hyperintensity analysis (e. g. ${ }^{62}$ ). Other common reasons for exclusion were region of interest analyses (e. g. ${ }^{63-65}$ ) and studies investigating subclinical samples not meeting AUD diagnosis criteria (e. g. ${ }^{66}$ ). Information about demographic and clinical sample characteristics from the included studies are presented in Table 1. Methodological features regarding data acquisition and analysis, as well as the source of reported peak-coordinates for each individual study can be found in supplementary Table S1. The quality assessment for the included studies revealed high concordance with the selected criterions (supplementary Table S2). General information regarding sample characteristics was given, but in a few cases specification of comorbidity and AUD duration or duration of abstinence appeared to be missing. Control groups were mainly matched and if not, in most cases, the authors integrated differences in age or sex as covariates in their analyses. Overall, MRI procedures and statistical analyses were described comprehensible and missing information was accessible after personal correspondence.

\subsection{ALE results}

ALE revealed four significant clusters of convergent macro- and microstructural WM alterations in AUD patients compared to healthy controls, which are shown in Figure 2. The largest cluster (C1) comprises parts of the mid body of the corpus callosum and the fornix in both hemispheres. The other clusters are mainly located in the right hemisphere and C2 also covers the posterior body of the corpus callosum 
with extension to the posterior cingulum bundle. The third cluster (C3) can be assigned to the right posterior limb of the internal capsule and the smallest and last cluster (C4) shows convergence in the genu of the corpus callosum with extension to the anterior cingulum bundle. The cluster sizes, peakcoordinates, and associated ALE values as well as the centers of mass are reported in Table 2.

\subsection{Diagnostics of ALE results and post-hoc analyses}

Overall, fourteen out of eighteen included studies contributed to the identified clusters of convergence. Most of them contributed to C1 (8 studies), followed by C2 (7 studies), C3 (5 studies) and C4 (4 studies). The contributing studies as well as the number of contributing foci and their respective WM measures and contrasts are summarized in supplementary Table S3. The convergence of C1-C4 mainly emerges from foci referring to contrasts of reduced WM volume/density or structural integrity (e. g. lower fractional anisotropy (FA) and higher mean-, radial- or axial diffusivity measures (MD, RD, $A D)$ of WM fiber tracts in AUD patients. Only for $\mathrm{C} 1$, one foci refers to an opposite contrast of higher FA values and for $\mathrm{C} 3$, one foci refers to a contrast of higher WM volume. One of the contributing studies used a joint independent component analysis (jICA) procedure and did not report the direction of individual effects of the integrated coefficients (FA, MD, RD $)^{44}$. The findings of this study can thus only be interpreted as a change in fiber integrity in AUD. Regarding the robustness of the meta-analytic results, the ALE clusters remained significant after adding $5 \%$ up to $283 \%$ noise studies (FSN). The calculated FSN values for each cluster are presented in the last column of Table 2.

\subsection{Exploratory subgroup analysis of DTI studies only}

An exploratory subgroup analysis based on data from studies applying DTI methods only $(n=11)$, revealed four clusters of convergent microstructural WM alterations (supplementary Table S4 and Figure S1). Three clusters cover similar locations as the main analysis and comprise the left fornix, the right body of the corpus callosum with extension to the posterior cingulum bundle and the right genu of the corpus callosum with extension to the anterior cingulum bundle. In contrast to the main analysis, the peak-coordinates of the studies in this subgroup did not show convergence in the mid body of the corpus callosum nor the right posterior limb of the internal capsule. An additional cluster appears in the left hemisphere located in the posterior parts of the left corpus callosum resulting from four contributing foci of four DTI studies ${ }^{13,44,58,59}$. 


\section{Discussion}

Following a systematic literature search to identify VBM and DTI studies on the localization of WM alterations in AUD, we conducted a coordinate-based neuroimaging meta-analysis, which revealed four significant clusters of convergent macro- and microstructural WM changes. The clusters covered parts of the genu and the body of the corpus callosum with extensions to the fornix as well as anterior and posterior cingulum bundle. Another cluster comprises the right posterior limb of the internal capsule. A similar pattern was observed when conducting the meta-analysis based on DTI studies only. The latter analysis revealed an additional cluster within the posterior parts of the left corpus callosum.

In this meta-analysis, we included contrasts that map both, reductions and increases in WM volume/density or WM integrity. In addition, we were able to integrate results from studies that used non-directional methods such as joint ICA ${ }^{44}$. This is possible because the ALE method itself tests directionally independent since it is not based on effect $\operatorname{sizes}^{28}$, which is particularly useful in the context of clinical samples, where the effects may vary over the course of the disorder (e.g. as a function of the duration of abstinence or changes in the proportion of grey to white matter) ${ }^{23,26}$. A close inspection of the contributing foci revealed that the ALE convergence clusters identified in our meta-analysis are largely based on studies that report a WM reduction in AUD patients.

The identified regions cover the anterior part of the body of the corpus callosum, which connects premotor and motor regions of both hemispheres and the genu of the corpus callosum connects large portions of the prefrontal cortices ${ }^{67,68}$. Another cluster of WM structure changes was located in the cingulum bundle which interconnects frontal, parietal and medial temporal brain regions as well as subcortical nuclei to the cingulate gyrus ${ }^{69}$. The posterior limb of the internal capsule comprises fibers that connect visual, auditory, somatosensory and motor regions ${ }^{70,71}$. Regarding the functional consequences, even subtle alterations in areas of the corpus callosum and cingulate bundle can lead to numerous functional impairments, as they represent important WM structures with interhemispheric and intrahemispheric pathways ${ }^{69,72}$, respectively.

WM alterations within these structures could explain to some extent the decline in motor, affective, perceptive and cognitive functions related to $A_{U D}{ }^{73}$. For example, AUD related alterations in callosal fibers are associated with changes in executive function ${ }^{44}$ and decision making deficits ${ }^{60}$. In particular, reduced integrity of the genu of the corpus callosum could be associated with poorer working memory performance ${ }^{74}$. However, another study could not find a direct correlation between the integrity of the callosal fibers and cognitive performance in AUD, but a correlation between the integrity of the cingulum, 
executive functions and psychomotor performance ${ }^{54}$. Furthermore, the cingulum bundle as well as the fornix form two major fiber tracts of the limbic system and their degradation might promote deficits in emotion regulation processes ${ }^{75}$. For example, lower FA in frontoparietal and corticolimbic networks as well as in deep WM structures, like the internal capsule, has been linked to higher alcohol cue reactivity in heavy drinkers ${ }^{76}$. In addition, lower visuo-spatial memory performance, another neurobehavioral consequences of heavy chronic alcohol consumption (e.g. ${ }^{77}$ for review), has been associated with reduced commissural FA in AUD patients compared to controls ${ }^{43}$. Furthermore, the corpus callosum and the cingulum have been found to interconnect key nodes of large-scale brain networks, such as the default mode network and the body of the corpus callosum connects left and right hemispheric parts of the primary sensorimotor network ${ }^{78}$.

In summary, the above examples point towards an association of WM changes in AUD patients identified by this meta-analysis and several behavioral impairments. Together with previously reported GM reductions in $A U D^{18}$, they may explain deterioration of a wide range of motor, cognitive, affective, and perceptual functions in individuals with AUD. However, the behavioral interpretation of our results is still speculative as it is based on a few single studies and as we could not apply a data-driven approach that is comparable to the workflows via the BrainMap database for GM data ${ }^{79}$. Thus, further studies are needed to explore the behavioral meaning of the WM changes in the identified clusters.

Despite the clear meta-analytical evidence for substantial changes of WM in AUD, the underlying molecular or cellular mechanisms remain unexplored. The studies contributing to the results of the main analysis measured volume or density and structural integrity. This may suggest that the changes in fiber tract integrity are simply due to alcohol-induced WM atrophy. In line with these suggestions, the subanalysis based on DTI studies only showed a similar pattern of ALE convergence clusters as the main analysis, but also revealed an additional cluster in the posterior left callosal fiber tract. It is thus possible that the detection of fiber tract integrity is a more sensitive measure than volume or density measurements may detect even smaller changes that lie deep in the WM. Those changes in integrity may also precede WM atrophy ${ }^{80}$. Consequently, the latter may only appear in the later course of the disorder or might no longer be detectable in the case of prolonged abstinence (see ${ }^{25}$ for volumetric meta-analysis). With respect to the DTI measures, it is possible that alcohol-induced reduction of myelin may be caused by inflammatory or epigenetic processes ${ }^{8,81}$. In addition, a reduction of axonal fibers may have occurred due to direct alcohol toxicity to neuronal and glia cells. Lastly, changes in the chemical composition of fibers as well as the ratio between axonal fibers, oligodendrocytes, and other 
glial cells in AUD patients may account for observed effects (e. g. ${ }^{12,81}$ for review). Together, chronic high alcohol consumption has been shown to cause multiple molecular and systemic changes that may account for observed WM alterations. In this regard, it is interesting to note structural damages observed in AUD patients partially regenerated during prolonged abstinence ${ }^{63}$. Alternatively or in addition, a preexisting state of WM alterations may also be the cause or at least facilitating the development of AUD, as for example in individuals with family history of AUD ${ }^{82}$.

Finally, it should be noted that the results of our analysis are not consistent with those of another recent meta-analysis ${ }^{26}$, where a pattern of convergent WM volumetric alterations in AUD in the corticospinal tract and anterior thalamic radiation has been identified. However, this meta-analysis was not explicitly designed to investigate WM alterations in AUD but reported respective findings as a part of a subanalysis in a broader context based on four studies only.

Although our work fills a gap regarding lacking meta-analytical evidence on WM alterations in AUD by strictly following state-of-the-art guidelines for neuroimaging meta-analyses (for checklist see supplementary table S5), it is subject to several limitations. First, even with pre-specified inclusion and exclusion criteria, the integrated studies are heterogeneous in certain aspects (e. g. sample characteristics like sex distribution, see Table 1). Second, in two studies the AUD samples comprised participants who reported co-consumption of other substances (e. g. $\left.{ }^{13,56}\right)$. Furthermore, there is a high range of overall abstinence durations between the studies included. Therefore, meta-regressions could be informative but unfortunately are not feasible in ALE analyses. Third, the ALE method is insensitive to non-significant results ${ }^{28}$ and is thus susceptible to potentially unobserved publication bias. To account for these uncertainties, we calculated a modified fail-safe $\mathrm{N}^{36}$ for each of the ALE convergence clusters. Respective results indicate that most clusters show stable effects against additional noise studies and are not driven by a few very dominant studies.

In conclusion, we identified four clusters of convergent macro- and microstructural WM alterations in patients with AUD through ALE meta-analysis. The resulting clusters have been assigned to key brain structures of cingulum, corpus callosum, fornix and internal capsule. Respective reductions in WM volume and axonal integrity may reflect either permanent or partly transient changes in AUD patients that have been associated with several neuropsychological deficits (e. g. decision making and emotion regulation) in functional neuroimaging studies ${ }^{60,76}$. Future research is needed to provide a more accurate behavioral assessment of the identified WM clusters and to examine the extent of reversibility of alcoholrelated WM changes. 


\section{Acknowledgements}

We would like to thank Silvia de Santis (Miguel Hernández University of Elche), Anne-Lise Pitel and Shailendra Segobin (University of Caen Normandy) as well as Gordon Harris (Harvard Medical School Boston) and Kayle Sawyer (Boston University) for the friendly and helpful personal correspondence and for supplying us with information and data of their research.

This work was supported by an intramural research fund (MSH Medical School Hamburg) to C.S.

\section{Conflict of Interest}

There is no conflict of interest to disclose.

\section{Authors Contribution}

C.S. carried out the literature search, data extraction and data analysis, prepared figures and tables and wrote the first draft of the manuscript. M.M. made substantial revisions to the manuscript and supervised the entire work. L.M. double checked literature search and data extraction, contributed significantly to the interpretation of the data, and reviewed the manuscript. S.T. and N.A. contributed significantly to the interpretation of the data and reviewed the manuscript. 


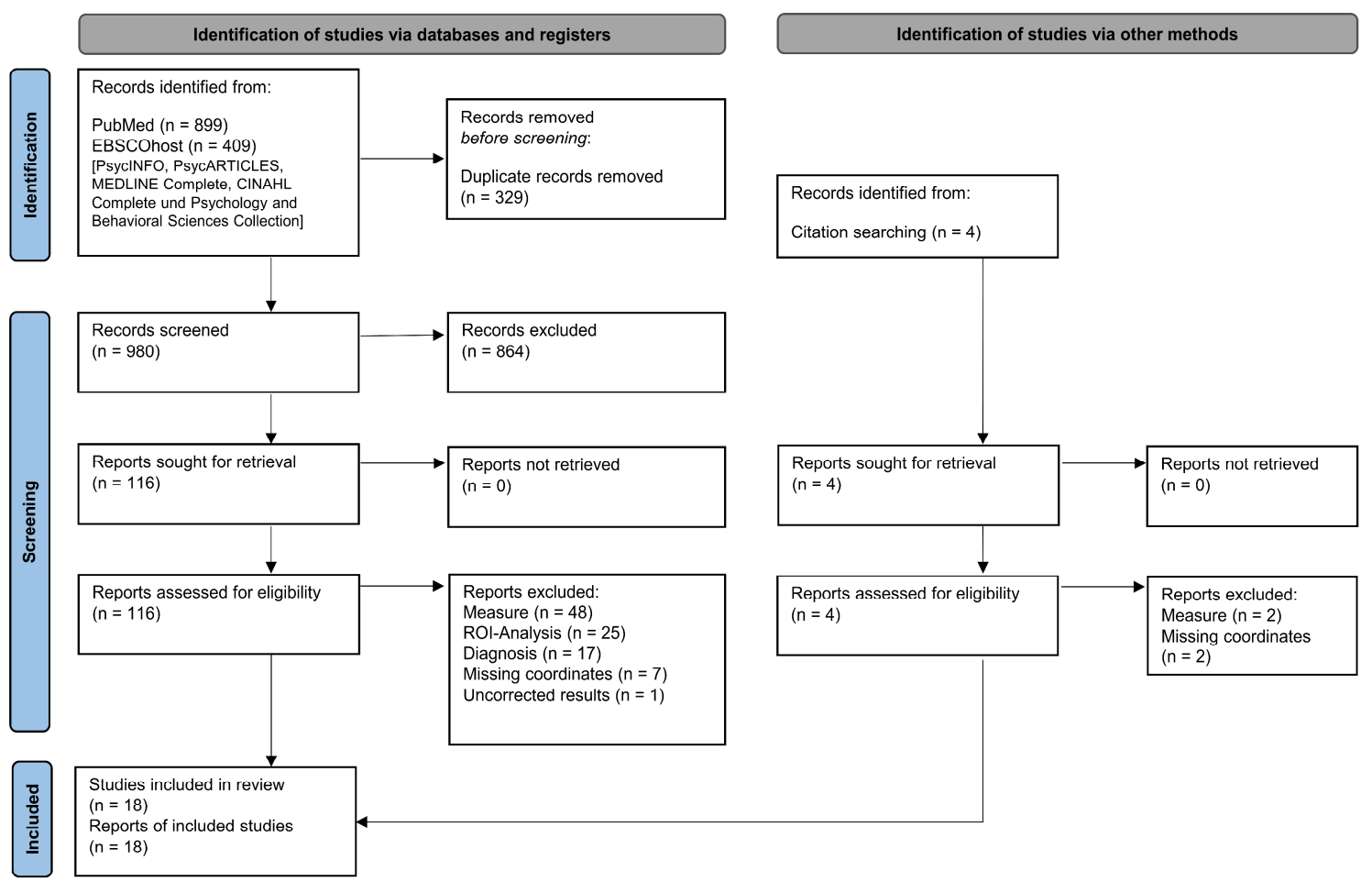

Fig. 1. Flow diagram on the different phases of the systematic literature search according to the PRISMA Guideline from Page et al. (2021) ${ }^{34}$. 

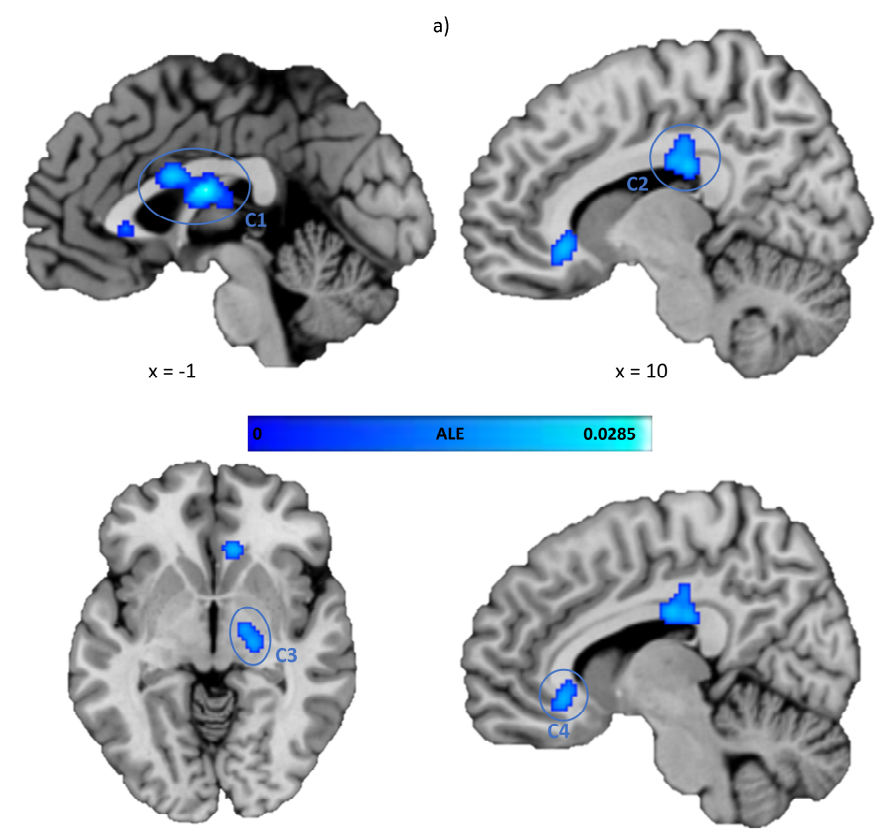

0.0285
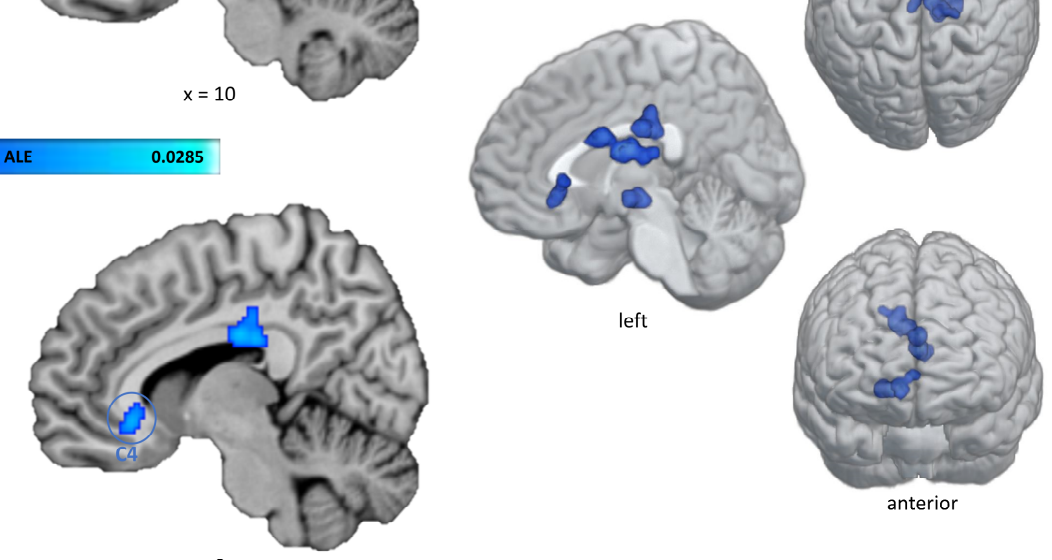

$z=-6$

$x=8$

Fig. 2. Results of the ALE meta-analysis. The highlighted clusters (C1-C4) represent significant convergence of white matter alterations in AUD patients compared to healthy controls. a) Clusters are depicted on brain slices of an MNI standard brain. Color indicates ALE value. b) Spatial location and expansion of the ALE-clusters depicted on a white matter glass brain. Cluster-forming threshold $p<$ 0.001, FWE cluster level corrected at $p<0.05 . \mathrm{x}, \mathrm{y}$ and $\mathrm{z}$ values refer to coordinates in MNI space, for detailed MNI peak voxel coordinates of the ALE clusters see table 2. This image was created with Mango (v4.1., http://ric.uthscsa.edu/mango/) and MRIcroGL (v1.2.20210317, https://www.mccauslandcenter.sc.edu/mricrogl/). 







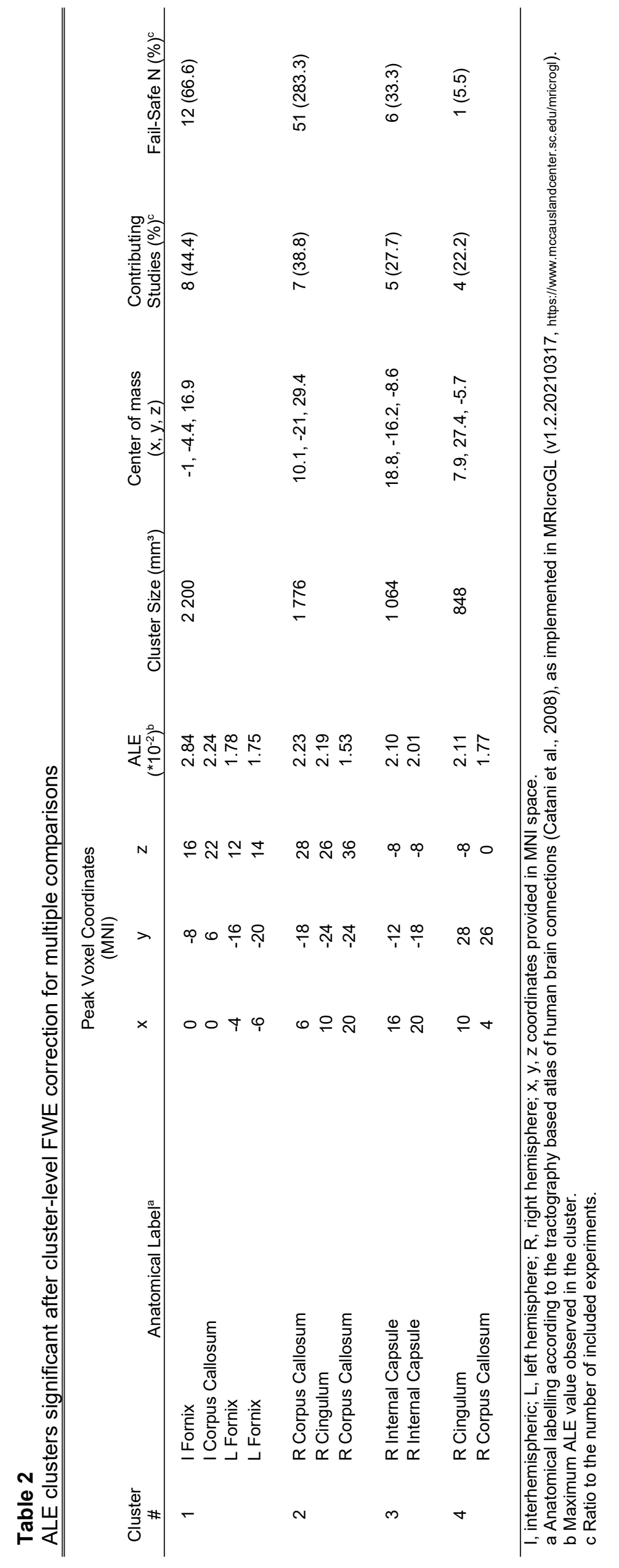




\section{References}

1 Peacock A, Leung J, Larney S, Colledge S, Hickman M, Rehm J et al. Global statistics on alcohol, tobacco and illicit drug use: 2017 status report. Addiction 2018; 113: 1905-1926.

2 Rehm J, Shield KD. Global Burden of Disease and the Impact of Mental and Addictive Disorders. Curr Psychiatry Rep 2019; 21: 10.

3 Shield KD, Parry C, Rehm J. Chronic Diseases and Conditions Related to Alcohol Use. Alcohol Res 2014; 35: 155-171.

4 Rumgay H, Shield K, Charvat H, Ferrari P, Sornpaisarn B, Obot I et al. Global burden of cancer in 2020 attributable to alcohol consumption: a population-based study. The Lancet Oncology 2021; 0. doi:10.1016/S1470-2045(21)00279-5.

5 Fritz M, Klawonn AM, Zahr NM. Neuroimaging in Alcohol Use Disorder: from mouse to man. J Neurosci Res 2019. doi:10.1002/jnr.24423.

6 Sullivan EV, Pfefferbaum A. Neurocircuitry in alcoholism: a substrate of disruption and repair. Psychopharmacology 2005; 180: 583-594.

7 Oscar-Berman M, Marinkovic K. Alcoholism and the Brain: An Overview. Alcohol Res Health 2003; 27: 125-133.

8 de la Monte SM, Kril JJ. Human alcohol-related neuropathology. Acta Neuropathol 2014; 127: 71-90.

9 Crews FT, Nixon K. Mechanisms of Neurodegeneration and Regeneration in Alcoholism. Alcohol Alcohol 2009; 44: 115-127.

10 Blaine SK, Sinha R. Alcohol, Stress, and Glucocorticoids: From Risk to Dependence and Relapse in Alcohol Use Disorders. Neuropharmacology 2017; 122: 136-147.

11 Stephens MAC, Wand G. Stress and the HPA axi: Role of glucocorticoids in alcohol dependence. Alcohol Research: Current Reviews 2012; 34: 468-483.

12 Rice J, Gu C. Function and Mechanism of Myelin Regulation in Alcohol Abuse and Alcoholism. BioEssays 2019; 41: 1800255.

13 Monnig MA, Caprihan A, Yeo RA, Gasparovic C, Ruhl DA, Lysne P et al. Diffusion Tensor Imaging of White Matter Networks in Individuals with Current and Remitted Alcohol Use Disorders and Comorbid Conditions. Psychol Addict Behav 2013; 27: 455465.

14 Demirakca T, Ende G, Kämmerer N, Welzel-Marquez H, Hermann D, Heinz A et al. Effects of Alcoholism and Continued Abstinence on Brain Volumes in Both Genders. Alcoholism: Clinical and Experimental Research 2011; 35: 1678-1685.

15 Brust JCM. Ethanol and Cognition: Indirect Effects, Neurotoxicity and Neuroprotection: A Review. Int J Environ Res Public Health 2010; 7: 1540-1557. 
16 Xiao P, Dai Z, Zhong J, Zhu Y, Shi H, Pan P. Regional gray matter deficits in alcohol dependence: A meta-analysis of voxel-based morphometry studies. Drug and Alcohol Dependence 2015; 153: 22-28.

17 Yang X, Tian F, Zhang H, Zeng J, Chen T, Wang S et al. Cortical and subcortical gray matter shrinkage in alcohol-use disorders: a voxel-based meta-analysis. Neuroscience \& Biobehavioral Reviews 2016; 66: 92-103.

18 Spindler C, Trautmann S, Alexander N, Bröning S, Bartscher S, Stuppe M et al. Metaanalysis of grey matter changes and their behavioral characterization in patients with alcohol use disorder. Scientific Reports 2021; 11: 5238.

19 Segobin SH, Chételat G, Le Berre A-P, Lannuzel C, Boudehent C, Vabret F et al. Relationship between brain volumetric changes and interim drinking at six months in alcohol-dependent patients. Alcohol Clin Exp Res 2014; 38: 739-748.

20 Asensio S, Morales JL, Senabre I, Romero MJ, Beltran MA, Flores-Bellver M et al. Magnetic resonance imaging structural alterations in brain of alcohol abusers and its association with impulsivity. Addict Biol 2016; 21: 962-971.

21 Fortier CB, Leritz EC, Salat DH, Lindemer E, Maksimovskiy AL, Shepel J et al. Widespread Effects of Alcohol on White Matter Microstructure. Alcoholism: Clinical and Experimental Research 2014; 38: 2925-2933.

22 Crespi C, Galandra C, Canessa N, Manera M, Poggi P, Basso G. Microstructural damage of white-matter tracts connecting large-scale networks is related to impaired executive profile in alcohol use disorder. NeuroImage: Clinical 2020; 25: 102141.

23 Hampton WH, Hanik IM, Olson IR. Substance abuse and white matter: Findings, limitations, and future of diffusion tensor imaging research. Drug Alcohol Depend 2019; 197: 288-298.

24 Elofson J, Gongvatana W, Carey KB. Alcohol Use and Cerebral White Matter Compromise in Adolescence. Addict Behav 2013; 38: 2295-2305.

25 Monnig MA, Tonigan JS, Yeo RA, Thoma RJ, McCrady BS. White matter volume in alcohol use disorders: a meta-analysis. Addict Biol 2013; 18: 581-592.

26 Pando-Naude V, Toxto S, Fernandez-Lozano S, Parsons CE, Alcauter S, Garza-Villarreal EA. Gray and white matter morphology in substance use disorders: a neuroimaging systematic review and meta-analysis. Transl Psychiatry 2021; 11: 29.

27 Tahmasian M, Sepehry AA, Samea F, Khodadadifar T, Soltaninejad Z, Javaheripour N et al. Practical recommendations to conduct a neuroimaging meta-analysis for neuropsychiatric disorders. Hum Brain Mapp 2019; 40: 5142-5154.

28 Müller VI, Cieslik EC, Laird AR, Fox PT, Radua J, Mataix-Cols D et al. Ten simple rules for neuroimaging meta-analysis. Neuroscience \& Biobehavioral Reviews 2018; 84: 151161.

29 Ashburner J, Friston KJ. Voxel-Based Morphometry-The Methods. NeuroImage 2000; 11: $805-821$. 
30 Mechelli A, J. Price C, J. Friston K, Ashburner J. Voxel-Based Morphometry of the Human Brain: Methods and Applications. Current Medical Imaging 2005; 1: 105-113.

31 Bihan DL, Mangin J-F, Poupon C, Clark CA, Pappata S, Molko N et al. Diffusion tensor imaging: Concepts and applications. Journal of Magnetic Resonance Imaging 2001; 13: $534-546$.

32 Mori S, Zhang J. Principles of Diffusion Tensor Imaging and Its Applications to Basic Neuroscience Research. Neuron 2006; 51: 527-539.

33 Vitolo E, Tatu MK, Pignolo C, Cauda F, Costa T, Ando' A et al. White matter and schizophrenia: A meta-analysis of voxel-based morphometry and diffusion tensor imaging studies. Psychiatry Research: Neuroimaging 2017; 270: 8-21.

34 Page MJ, McKenzie JE, Bossuyt PM, Boutron I, Hoffmann TC, Mulrow CD et al. The PRISMA 2020 statement: an updated guideline for reporting systematic reviews. $B M J$ 2021; 372: n71.

35 Nichols TE, Das S, Eickhoff SB, Evans AC, Glatard T, Hanke M et al. Best practices in data analysis and sharing in neuroimaging using MRI. Nat Neurosci 2017; 20: 299-303.

36 Acar F, Seurinck R, Eickhoff SB, Moerkerke B. Assessing robustness against potential publication bias in Activation Likelihood Estimation (ALE) meta-analyses for fMRI. PLOS ONE 2018; 13: e0208177.

37 Eickhoff SB, Laird AR, Grefkes C, Wang LE, Zilles K, Fox PT. Coordinate-based activation likelihood estimation meta-analysis of neuroimaging data: A random-effects approach based on empirical estimates of spatial uncertainty. Hum Brain Mapp 2009; 30: 2907-2926.

38 Eickhoff SB, Bzdok D, Laird AR, Kurth F, Fox PT. Activation likelihood estimation meta-analysis revisited. Neuroimage 2012; 59: 2349-2361.

39 Jenkinson M, Beckmann CF, Behrens TEJ, Woolrich MW, Smith SM. FSL. Neuroimage 2012; 62: 782-790.

40 Lancaster JL, Tordesillas-Gutiérrez D, Martinez M, Salinas F, Evans A, Zilles K et al. Bias between MNI and Talairach coordinates analyzed using the ICBM-152 brain template. Hum Brain Mapp 2007; 28: 1194-1205.

41 Laird AR, Robinson JL, McMillan KM, Tordesillas-Gutiérrez D, Moran ST, Gonzales SM et al. Comparison of the disparity between Talairach and MNI coordinates in functional neuroimaging data: Validation of the Lancaster transform. Neuroimage 2010; 51: $677-683$.

42 Turkeltaub PE, Eickhoff SB, Laird AR, Fox M, Wiener M, Fox P. Minimizing withinexperiment and within-group effects in activation likelihood estimation meta-analyses. Hum Brain Mapp 2011; 33: 1-13.

43 Yeh P-H, Simpson K, Durazzo TC, Gazdzinski S, Meyerhoff DJ. Tract-Based Spatial Statistics (TBSS) of diffusion tensor imaging data in alcohol dependence: abnormalities of the motivational neurocircuitry. Psychiatry Res 2009; 173: 22-30. 
44 Crespi C, Galandra C, Manera M, Basso G, Poggi P, Canessa N. Executive Impairment in Alcohol Use Disorder Reflects Structural Changes in Large-Scale Brain Networks: A Joint Independent Component Analysis on Gray-Matter and White-Matter Features. Front Psychol 2019; 10. doi:10.3389/fpsyg.2019.02479.

45 Harris GJ, Jaffin SK, Hodge SM, Kennedy D, Caviness VS, Marinkovic K et al. Frontal White Matter and Cingulum Diffusion Tensor Imaging Deficits in Alcoholism. Alcohol Clin Exp Res 2008; 32: 1001-1013.

46 Eickhoff SB, Nichols TE, Laird AR, Hoffstaedter F, Amunts K, Fox PT et al. Behavior, Sensitivity, and power of activation likelihood estimation characterized by massive empirical simulation. Neuroimage 2016; 137: 70-85.

47 Talairach, J., Tournoux, P. Co-Planar Stereotaxic Atlas of the Human Brain. Thieme Medical Publishers: New York, 1988.

48 Mori S, Oishi K, Faria AV. White matter atlases based on diffusion tensor imaging. Curr Opin Neurol 2009; 22: 362-369.

49 Catani M, Thiebaut de Schotten M. A diffusion tensor imaging tractography atlas for virtual in vivo dissections. Cortex 2008; 44: 1105-1132.

50 Chanraud S, Martelli C, Delain F, Kostogianni N, Douaud G, Aubin H-J et al. Brain Morphometry and Cognitive Performance in Detoxified Alcohol-Dependents with Preserved Psychosocial Functioning. Neuropsychopharmacology 2007; 32: 429-438.

51 Chumin EJ, Goñi J, Halcomb ME, Durazzo TC, Dzemidzic M, Yoder KK. Differences in White Matter Microstructure and Connectivity in Nontreatment-Seeking Individuals with Alcohol Use Disorder. Alcoholism: Clinical and Experimental Research 2018; 42: 889896.

52 De Santis S, Bach P, Pérez-Cervera L, Cosa-Linan A, Weil G, Vollstädt-Klein S et al. Microstructural White Matter Alterations in Men With Alcohol Use Disorder and Rats With Excessive Alcohol Consumption During Early Abstinence. JAMA Psychiatry 2019; 76: 749-758.

53 Jang D-P, Namkoong K, Kim J-J, Park S, Kim I-Y, Kim SI et al. The relationship between brain morphometry and neuropsychological performance in alcohol dependence. Neuroscience Letters 2007; 428: 21-26.

54 Konrad A, Vucurevic G, Lorscheider M, Bernow N, Thümmel M, Chai C et al. Broad Disruption of Brain White Matter Microstructure and Relationship with Neuropsychological Performance in Male Patients with Severe Alcohol Dependence. Alcohol and Alcoholism 2012; 47: 118-126.

55 Mechtcheriakov S, Brenneis C, Egger K, Koppelstaetter F, Schocke M, Marksteiner J. A widespread distinct pattern of cerebral atrophy in patients with alcohol addiction revealed by voxel-based morphometry. Journal of Neurology, Neurosurgery \& Psychiatry 2007; 78: $610-614$.

56 Pandey AK, Ardekani BA, Kamarajan C, Zhang J, Chorlian DB, Byrne KN-H et al. Lower Prefrontal and Hippocampal Volume and Diffusion Tensor Imaging Differences 
Reflect Structural and Functional Abnormalities in Abstinent Individuals with Alcohol Use Disorder. Alcoholism: Clinical and Experimental Research 2018; 42: 1883-1896.

57 Pitel A-L, Chételat G, Berre APL, Desgranges B, Eustache F, Beaunieux H.

Macrostructural abnormalities in Korsakoff syndrome compared with uncomplicated alcoholism. Neurology 2012; 78: 1330-1333.

58 Sawyer KS, Maleki N, Papadimitriou G, Makris N, Oscar-Berman M, Harris GJ. Cerebral white matter sex dimorphism in alcoholism: a diffusion tensor imaging study.

Neuropsychopharmacology 2018; 43: 1876-1883.

59 Segobin S, Ritz L, Lannuzel C, Boudehent C, Vabret F, Eustache F et al. Integrity of white matter microstructure in alcoholics with and without Korsakoff's syndrome. Hum Brain Mapp 2015; 36: 2795-2808.

60 Zorlu N, Gelal F, Kuserli A, Cenik E, Durmaz E, Saricicek A et al. Abnormal white matter integrity and decision-making deficits in alcohol dependence. Psychiatry Res 2013; 214: $382-388$.

61 Kuceyeski A, Meyerhoff DJ, Durazzo TC, Raj A. Loss in connectivity among regions of the brain reward system in alcohol dependence. Hum Brain Mapp 2012; 34: 3129-3142.

62 Fein G, Shimotsu R, Di Sclafani V, Barakos J, Harper C. Increased white matter signal hyperintensities in long-term abstinent alcoholics compared with nonalcoholic controls. Alcohol Clin Exp Res 2009; 33: 70-78.

63 Alhassoon OM, Sorg SF, Taylor MJ, Stephan RA, Schweinsburg BC, Stricker NH et al. Callosal White Matter Microstructural Recovery in Abstinent Alcoholics: A Longitudinal Diffusion Tensor Imaging Study. Alcohol Clin Exp Res 2012; 36: 1922-1931.

64 Chanraud S, Reynaud M, Wessa M, Penttilä J, Kostogianni N, Cachia A et al. Diffusion Tensor Tractography in Mesencephalic Bundles: Relation to Mental Flexibility in Detoxified Alcohol-Dependent Subjects. Neuropsychopharmacology 2009; 34: 12231232.

65 Pfefferbaum A, Sullivan EV. Disruption of Brain White Matter Microstructure by Excessive Intracellular and Extracellular Fluid in Alcoholism: Evidence from Diffusion Tensor Imaging. Neuropsychopharmacology 2005; 30: 423-432.

66 Sachdev PS, Chen X, Wen W, Anstry KJ. Light to moderate alcohol use is associated with increased cortical gray matter in middle-aged men: A voxel-based morphometric study. Psychiatry Research: Neuroimaging 2008; 163: 61-69.

67 Fortin D, Aubin-Lemay C, Boré A, Girard G, Houde J-C, Whittingstall K et al. Tractography in the Study of the Human Brain: A Neurosurgical Perspective. Can J Neurol Sci 2012; 39: 747-756.

68 Hofer S, Frahm J. Topography of the human corpus callosum revisited-Comprehensive fiber tractography using diffusion tensor magnetic resonance imaging. NeuroImage 2006; 32: 989-994.

69 Bubb EJ, Metzler-Baddeley C, Aggleton JP. The cingulum bundle: Anatomy, function, and dysfunction. Neuroscience \& Biobehavioral Reviews 2018; 92: 104-127. 
70 Chowdhury F, Haque M, Sarkar M, Ara S, Islam M. White fiber dissection of brain; the internal capsule: a cadaveric study. Turk Neurosurg 2010; 20: 314-322.

71 Lemaire J-J, Cosnard G, Sakka L, Nuti C, Gradkowski W, Mori S et al. White matter anatomy of the human deep brain revisited with high resolution DTI fibre tracking. Neurochirurgie 2011; 57: 52-67.

72 van der Knaap LJ, van der Ham IJM. How does the corpus callosum mediate interhemispheric transfer? A review. Behavioural Brain Research 2011; 223: 211-221.

73 Le Berre A-P, Fama R, Sullivan EV. Executive Functions, Memory, and Social Cognitive Deficits and Recovery in Chronic Alcoholism: A Critical Review to Inform Future Research. Alcohol Clin Exp Res 2017; 41: 1432-1443.

74 Pfefferbaum A, Adalsteinsson E, Sullivan EV. Neurobiology of Aging 2006; 27: 9941009.

75 Schulte T, Müller-Oehring EM, Pfefferbaum A, Sullivan EV. Neurocircuitry of emotion and cognition in alcoholism: contributions from white matter fiber tractography. Dialogues Clin Neurosci 2010; 12: 554-560.

76 Monnig MA, Thayer RE, Caprihan A, Claus ED, Yeo RA, Calhoun VD et al. White matter integrity is associated with alcohol cue reactivity in heavy drinkers. Brain Behav 2014; 4: 158-170.

77 Oscar-Berman M, Marinković K. Alcohol: Effects on Neurobehavioral Functions and the Brain. Neuropsychol Rev 2007; 17: 239-257.

78 van den Heuvel MP, Mandl RCW, Kahn RS, Hulshoff Pol HE. Functionally linked resting-state networks reflect the underlying structural connectivity architecture of the human brain. Hum Brain Mapp 2009; 30: 3127-3141.

79 Lancaster JL, Laird AR, Eickhoff SB, Martinez MJ, Fox PM, Fox PT. Automated regional behavioral analysis for human brain images. Front Neuroinform 2012; 6. doi:10.3389/fninf.2012.00023.

80 Hugenschmidt CE, Peiffer AM, Kraft RA, Casanova R, Deibler AR, Burdette JH et al. Relating imaging indices of white matter integrity and volume in healthy older adults. Cereb Cortex 2008; 18: 433-442.

81 Harper C. The neuropathology of alcohol-related brain damage. Alcohol Alcohol 2009; 44: $136-140$.

82 Cservenka A. Neurobiological phenotypes associated with a family history of alcoholism. Drug Alcohol Depend 2016; 158: 8-21. 


\section{Supplementary Material}

\section{A coordinate-based meta-analysis of white matter alterations \\ in patients with alcohol use disorder}

Carolin Spindler ${ }^{1}$, Louisa Mallien², Sebastian Trautmann ${ }^{1}$, Nina Alexander ${ }^{1}$ and Markus Muehlhan ${ }^{1 *}$.

1) Department of Psychology, Faculty of Human Sciences, Medical School Hamburg, Am Kaiserkai 1, 20457 Hamburg, Germany

2) Department of Human Medicine, Faculty of Medicine, Medical School Hamburg, Am Kaiserkai 1, 20457 Hamburg, Germany 
Table S1

Methodological characteristics of the studies included in the ALE meta-analysis.

\begin{tabular}{|c|c|c|c|c|c|c|c|c|c|c|c|c|c|c|}
\hline \# & Source & $\begin{array}{c}\text { Field } \\
\text { strength }\end{array}$ & Method & $\begin{array}{l}\text { Smooth } \\
\text { Kernel }\end{array}$ & $\begin{array}{c}\text { Diffusion } \\
\text { Gradient } \\
\text { Directions }\end{array}$ & Software & Correction & Threshold & Covariates & Measure & Contrasts & $\begin{array}{l}\text { No. of } \\
\text { Foci }\end{array}$ & $\begin{array}{c}\text { Ref. } \\
\text { Space }\end{array}$ & $\begin{array}{c}\text { Source of } \\
\text { coordinates }\end{array}$ \\
\hline 1 & $\begin{array}{l}\text { Asensio et al. } \\
(2016)\end{array}$ & $1.5 \mathrm{~T}$ & VBM & $8 \mathrm{~mm}$ & - & SPM5 & $\mathrm{k} \geq 50$ & $p<0.05$ & $\begin{array}{l}\text { age, total } \\
\text { GMV and } \\
\text { WMV }\end{array}$ & Volume & $\begin{array}{l}\text { AUD }>\mathrm{HC} \\
\text { AUD }<\mathrm{HC}\end{array}$ & $\begin{array}{l}2 \\
2\end{array}$ & $\mathrm{MNI}$ & Table 2 \\
\hline 2 & $\begin{array}{l}\text { Chanraud et al. } \\
(2007)\end{array}$ & $1.5 \mathrm{~T}$ & VBM & $8 \mathrm{~mm}$ & - & SPM2 & $\begin{array}{l}\text { FDR } \\
k \geq 50\end{array}$ & $p<0.005$ & $\begin{array}{l}\text { age, } \\
\text { education, } \\
\text { smoking }\end{array}$ & Volume & $\mathrm{AUD}<\mathrm{HC}$ & 12 & MNI & Table 3 \\
\hline 3 & $\begin{array}{l}\text { Chumin et al. } \\
\text { (2018) }\end{array}$ & $3 T$ & DWI/TBSS & - & 48 & FSL & $\begin{array}{l}\text { TFCE, } \\
\text { FWE }\end{array}$ & $p<0.05$ & - & FA & $\mathrm{AUD}<\mathrm{HC}$ & 33 & MNI & Table S1 \\
\hline 4 & $\begin{array}{l}\text { Crespi et al. } \\
(2019)\end{array}$ & $3 \mathrm{~T}$ & $\begin{array}{l}\text { DTI/TBSS } \\
\text { (jICA) }\end{array}$ & - & 81 & $\mathrm{FSL}$ & $k \geq 10$ & $p=0.004$ & - & $\begin{array}{l}F A, A D, M D, \\
R D\end{array}$ & n. a. & 113 & MNI & Table S2-4 \\
\hline 5 & $\begin{array}{l}\text { Demirakca et al. } \\
\text { (2011) }\end{array}$ & $1.5 \mathrm{~T}$ & VBM & $8 \mathrm{~mm}$ & - & SPM8 & FWE & $p<0.05$ & age, sex, TIV & Volume & $\mathrm{AUD}<\mathrm{HC}$ & 7 & MNI & Table S5 \\
\hline 6 & $\begin{array}{l}\text { De Santis et al. } \\
\text { (2019) }\end{array}$ & $3 T$ & DTI/TBSS & - & 41 & $\begin{array}{l}\text { Explore } \\
\text { DTI, FSL }\end{array}$ & $\begin{array}{l}\text { TFCE, } \\
\text { FWE }\end{array}$ & $p<0.05$ & age & $\begin{array}{l}\mathrm{FA}, \\
\mathrm{MD}\end{array}$ & $\begin{array}{l}\text { AUD }<H C \\
A U D>H C\end{array}$ & $\begin{array}{l}7 \\
8\end{array}$ & MNI & p.c. \\
\hline 7 & $\begin{array}{l}\text { Harris et al. } \\
(2008)\end{array}$ & $3 T$ & DTI & $8 \mathrm{~mm}$ & 6 & SPM, FSL & $k \geq 5^{\text {p. c. }}$ & $p<0.01$ & age & FA & $\begin{array}{l}A U D<H C \\
A U D>H C\end{array}$ & $\begin{array}{l}5 \\
1\end{array}$ & TAL & Table 3 \\
\hline 8 & $\begin{array}{l}\text { Jang et al. } \\
(2007)\end{array}$ & $3 T$ & VBM & $8 \mathrm{~mm}$ & - & $\begin{array}{l}\text { ANA-LYZE } \\
\text { SPM2 }\end{array}$ & $\begin{array}{l}\text { FDR } \\
k \geq 100\end{array}$ & $p<0.05$ & - & Density & $\mathrm{AUD}<\mathrm{HC}$ & 6 & TAL & Table 3 \\
\hline 9 & $\begin{array}{l}\text { Konrad et al. } \\
(2012)\end{array}$ & $1.5 \mathrm{~T}$ & DTI/TBSS & $6 \mathrm{~mm}$ & 6 & $\begin{array}{l}\text { MRIcro } \\
\text { FSL } \\
\text { SPM5 }\end{array}$ & FWE & $p<0.05$ & - & FA & $\mathrm{AUD}<\mathrm{HC}$ & 8 & MNI & Table 2 \\
\hline 10 & $\begin{array}{l}\text { Mechtcheriakov } \\
\text { et al. (2007) }\end{array}$ & $1.5 \mathrm{~T}$ & VBM & $10 \mathrm{~mm}$ & - & SPM2 & FDR & $p<0.05$ & $\begin{array}{l}\text { global mean } \\
\text { voxel values, } \\
\text { TIV }\end{array}$ & Volume & $\mathrm{AUD}<\mathrm{HC}$ & 3 & MNI & Table 2 \\
\hline 11 & $\begin{array}{l}\text { Monnig et al. } \\
\text { (2013) }\end{array}$ & $3 \mathrm{~T}$ & DTI/TBSS & - & 30 & FSL & $\begin{array}{l}\text { TFCE } \\
k \geq 100\end{array}$ & $p<0.05$ & - & FA & $A U D^{C+R}<H C$ & 3 & MNI & Table 2 \\
\hline
\end{tabular}




\section{Table S1 continued}

\begin{tabular}{|c|c|c|c|c|c|c|c|c|c|c|c|c|c|c|}
\hline 12 & $\begin{array}{l}\text { Pandey et al. } \\
\text { (2018) }\end{array}$ & $3 T$ & DTI & - & 30 & FreeSurfer & FWE & $p<0.05$ & age & $\begin{array}{l}\mathrm{FA}, \mathrm{MD}, \mathrm{AD}, \\
\mathrm{RD}\end{array}$ & $\begin{array}{l}\text { AUD }<H C \\
A U D>H C\end{array}$ & 10 & MNI & Table 2 \\
\hline 13 & $\begin{array}{l}\text { Pitel et al. } \\
\text { (2012) }\end{array}$ & $1.5 \mathrm{~T}$ & VBM & $10 \mathrm{~mm}$ & - & SPM5 & $\begin{array}{l}\text { FDR } \\
k \geq 200\end{array}$ & $p<0.01$ & age, sex & Volume & $A U D<H C$ & 23 & MNI & p. c. \\
\hline 14 & $\begin{array}{l}\text { Sawyer et al. } \\
\text { (2018) }\end{array}$ & $3 \mathrm{~T}$ & DTI/TBSS & - & 60 & FSL & $\begin{array}{l}\text { TFCE, } \\
\text { FWE }\end{array}$ & $p<0.05$ & - & FA & $A U D<H C$ & 1 & TAL & Table 2 \\
\hline 15 & $\begin{array}{l}\text { Segobin et al. } \\
(2014)\end{array}$ & $1.5 \mathrm{~T}$ & VBM & $8 \mathrm{~mm}$ & - & SPM5 & $\begin{array}{l}\text { FDR } \\
k \geq 500\end{array}$ & $p<0.01$ & age & Volume & $\mathrm{AUD}<\mathrm{HC}$ & 4 & MNI & Figure 1 \\
\hline 16 & $\begin{array}{l}\text { Segobin et al. } \\
(2015)\end{array}$ & $3 \mathrm{~T}$ & DTI/TBSS & - & 32 & FSL & $\begin{array}{l}\text { TFCE, } \\
\text { FWE }\end{array}$ & $p<0.05$ & age & FA & $\mathrm{AUD}<\mathrm{HC}$ & 48 & MNI & p.c. \\
\hline 17 & $\begin{array}{l}\text { Yeh et al. } \\
\text { (2009) }\end{array}$ & $1.5 \mathrm{~T}$ & DTI/TBSS & n. a. & 6 & FSL & $\begin{array}{l}\text { FDR } \\
k \geq 200\end{array}$ & $p<0.05$ & age & $\begin{array}{l}F A, M D \\
A D, R D\end{array}$ & $\begin{array}{l}\text { AUD }<\mathrm{HC} \\
\text { AUD }>\mathrm{HC}\end{array}$ & 62 & MNI & Table 1 \\
\hline 18 & $\begin{array}{l}\text { Zorlu et al. } \\
\text { (2013) }\end{array}$ & $1.5 \mathrm{~T}$ & DTI/TBSS & - & 100 & FSL & TFCE & $p<0.05$ & - & $F A, A D, R D$ & $\begin{array}{l}A U D<H C \\
A U D>H C\end{array}$ & 4 & MNI & Table 2 \\
\hline
\end{tabular}

n.a.= information not available, VBM= voxel based morphometry, DTI= diffusion tensor imaging, TBSS= tract based spatial statistics, jICA= joint independent component analysis, SPM= Statistical Parametric Mapping, FSL= FMRIB Software Library, k= cluster size in voxels, FDR= False Discovery Rate, FWE= Family Wise Error Correction, TFCE= Threshold-free Cluster Enhancement , GMV= Gray matter volume, $\mathrm{WMV}=$ White matter volume, $\mathrm{TIV}=$ Total intracranial volume, $\mathrm{FA}=$ fractional anisotropy, $\mathrm{AD}=$ axial diffusivity, $\mathrm{MD}=$ mean diffusivity, $\mathrm{RD}=$ radial diffusivity, ${ }^{\mathrm{C}+\mathrm{R}}$ the authors subdivided the AUD patients in "current" and "early remission" groups but also reported results of a combined contrast which we included in our analysis, MNI= Montreal Neurological Institute, TAL= Talairach, p.c.= personal correspondence. 


\begin{tabular}{|c|c|c|c|c|c|c|c|c|c|c|c|c|c|c|c|c|c|c|}
\hline Quality criterion & \multicolumn{18}{|c|}{ Study number } \\
\hline & 1 & 2 & 3 & 4 & 5 & 6 & 7 & 8 & 9 & 10 & 11 & 12 & 13 & 14 & 15 & 16 & 17 & 18 \\
\hline \multicolumn{19}{|l|}{ Report of clinical sample characteristics } \\
\hline - $\quad$ Sample size $(\geq 10)$ & $\checkmark$ & $\checkmark$ & $\checkmark$ & $\checkmark$ & $\checkmark$ & $\checkmark$ & $\checkmark$ & $\checkmark$ & $\checkmark$ & $\checkmark$ & $\checkmark$ & $\checkmark$ & $\checkmark$ & $\checkmark$ & $\checkmark$ & $\checkmark$ & $\checkmark$ & $\checkmark$ \\
\hline - Mean age and sex distribution & $\checkmark$ & $\checkmark$ & $\checkmark$ & $\checkmark$ & $\checkmark$ & $\checkmark$ & $\checkmark$ & $\checkmark$ & $\checkmark$ & $\checkmark$ & $\checkmark$ & $\checkmark$ & $\checkmark$ & $\checkmark$ & $\checkmark$ & $\checkmark$ & $\checkmark$ & $\checkmark$ \\
\hline - $\quad$ Diagnosis criteria & $\checkmark$ & $\checkmark$ & $\checkmark$ & $\checkmark$ & $\checkmark$ & $\checkmark$ & $\checkmark$ & $\checkmark$ & $\checkmark$ & $\checkmark$ & $\checkmark$ & $\checkmark$ & $\checkmark$ & $\checkmark$ & $\checkmark$ & $\checkmark$ & $\checkmark$ & $\checkmark$ \\
\hline - $\quad$ Comorbidity & $\checkmark$ & $\checkmark$ & $\checkmark$ & $\checkmark$ & $\checkmark$ & $\checkmark$ & $\checkmark$ & $\checkmark$ & $\checkmark$ & $\checkmark$ & $\checkmark$ & $?$ & $\checkmark$ & $?$ & $\checkmark$ & $\checkmark$ & $\checkmark$ & $\checkmark$ \\
\hline - $\quad$ Duration of AUD & $\checkmark$ & $\checkmark$ & $x$ & $\checkmark$ & $\checkmark$ & $x$ & $\checkmark$ & $x$ & $\checkmark$ & $\checkmark$ & $x$ & $x$ & $\checkmark$ & $\checkmark$ & $\checkmark$ & $\checkmark$ & $x$ & $\checkmark$ \\
\hline - Duration of abstinence & $\checkmark$ & $\checkmark$ & $x$ & $\checkmark$ & $\checkmark$ & $\checkmark$ & $\checkmark$ & $\checkmark$ & $x$ & $\checkmark$ & $\checkmark$ & $\checkmark$ & $\checkmark$ & $\checkmark$ & $\checkmark$ & $\checkmark$ & $\checkmark$ & $\checkmark$ \\
\hline \multicolumn{19}{|l|}{ Description of control group } \\
\hline - $\quad$ Sample size $(\geq 10)$ & $\checkmark$ & $\checkmark$ & $\checkmark$ & $\checkmark$ & $\checkmark$ & $\checkmark$ & $\checkmark$ & $\checkmark$ & $\checkmark$ & $\checkmark$ & $\checkmark$ & $\checkmark$ & $\checkmark$ & $\checkmark$ & $\checkmark$ & $\checkmark$ & $=10$ & $\checkmark$ \\
\hline - $\quad$ Matched on age and sex & $\checkmark$ & $\checkmark$ & $\checkmark$ & $\checkmark$ & $\checkmark$ & \begin{tabular}{l|l}
$x$ & $\checkmark$
\end{tabular} & $\checkmark$ & $\checkmark$ & $\checkmark$ & $\checkmark$ & $\checkmark \mid x$ & \begin{tabular}{l|l}
$x$ & $\checkmark$
\end{tabular} & \begin{tabular}{l|l}
$\checkmark$ & $x$
\end{tabular} & $\checkmark$ & \begin{tabular}{l|l}
$\checkmark$ & $?$
\end{tabular} & \begin{tabular}{l|l}
$\checkmark$ & $x$
\end{tabular} & $\checkmark$ & $\checkmark$ \\
\hline \multicolumn{19}{|l|}{ Information given on MRI procedures } \\
\hline - Imaging parameters & $\checkmark$ & $\checkmark$ & $\checkmark$ & $\checkmark$ & $\checkmark$ & $\checkmark$ & $\checkmark$ & $\checkmark$ & $\checkmark$ & $\checkmark$ & $\checkmark$ & $\checkmark$ & $\checkmark$ & $\checkmark$ & $\checkmark$ & $\checkmark$ & $\checkmark$ & $\checkmark$ \\
\hline - $\quad$ Acquisition methods & $\checkmark$ & $\checkmark$ & $\checkmark$ & $\checkmark$ & $\checkmark$ & $\checkmark$ & $\checkmark$ & $\checkmark$ & $\checkmark$ & $\checkmark$ & $\checkmark$ & $\checkmark$ & $\checkmark$ & $\checkmark$ & $\checkmark$ & $\checkmark$ & $\checkmark$ & $\checkmark$ \\
\hline - Whole brain coverage & $\checkmark$ & $\checkmark$ & $\checkmark$ & $\checkmark$ & $\checkmark$ & $\checkmark$ & $\checkmark$ & $\checkmark$ & $\checkmark$ & $\checkmark$ & $\checkmark$ & $\checkmark$ & $\checkmark$ & $\checkmark$ & $\checkmark$ & $\checkmark$ & $\checkmark$ & $\checkmark$ \\
\hline - $\quad$ Standard reference space & $\checkmark$ & $\checkmark$ & $\checkmark$ & $\checkmark$ & $\checkmark$ & $\checkmark$ & $\checkmark$ & $\checkmark$ & $\checkmark$ & $\checkmark$ & $\checkmark$ & $\checkmark$ & $\checkmark$ & $\checkmark$ & $\checkmark$ & $\checkmark$ & $\checkmark$ & $\checkmark$ \\
\hline - Image processing & $\checkmark$ & $\checkmark$ & $\checkmark$ & $\checkmark$ & $\checkmark$ & $\checkmark$ & $\checkmark$ & $\checkmark$ & $\checkmark$ & $\checkmark$ & $\checkmark$ & $\checkmark$ & $\checkmark$ & $\checkmark$ & $\checkmark$ & $\checkmark$ & $\checkmark$ & $\checkmark$ \\
\hline \multicolumn{19}{|l|}{ Information given on statistical analysis } \\
\hline - $\quad$ Modelling approach & $\checkmark$ & $\checkmark$ & $\checkmark$ & $\checkmark$ & $\checkmark$ & $\checkmark$ & $\checkmark$ & $\checkmark$ & $\checkmark$ & $\checkmark$ & $\checkmark$ & $\checkmark$ & $\checkmark$ & $\checkmark$ & $\checkmark$ & $\checkmark$ & $\checkmark$ & $\checkmark$ \\
\hline - $\quad$ Software used & $\checkmark$ & $\checkmark$ & $\checkmark$ & $\checkmark$ & $\checkmark$ & $\checkmark$ & $\checkmark$ & $\checkmark$ & $\checkmark$ & $\checkmark$ & $\checkmark$ & $\checkmark$ & $\checkmark$ & $\checkmark$ & $\checkmark$ & $\checkmark$ & $\checkmark$ & $\checkmark$ \\
\hline - $\quad$ Correction for multiple comparisons & $x^{*}$ & $\checkmark$ & $\checkmark$ & $\checkmark$ & $\checkmark$ & $\checkmark$ & $x * / * *$ & $\checkmark$ & $\checkmark$ & $\checkmark$ & $\checkmark$ & $\checkmark$ & $\checkmark$ & $\checkmark$ & $\checkmark$ & $\checkmark$ & $\checkmark$ & $\checkmark$ \\
\hline \multicolumn{19}{|l|}{ Presentation of results } \\
\hline - Table of peak coordinates & $\checkmark$ & $\checkmark$ & $\checkmark$ & $\checkmark$ & $\checkmark$ & $x^{* *}$ & $\checkmark$ & $\checkmark$ & $\checkmark$ & $\checkmark$ & $\checkmark$ & $\checkmark$ & $\mathbf{x * *}$ & $\checkmark$ & $\checkmark$ & $x^{* *}$ & $\checkmark$ & $\checkmark$ \\
\hline
\end{tabular}

$\checkmark=$ study meets criterion, ? = unclear/information is not given, $\mathbf{x}=$ study does not meet criterion, ${ }^{*}=$ setting minimum cluster sizes instead, ${ }^{* *}=$ information received through personal correspondence 


\section{Study References}

1 Asensio S, Morales JL, Senabre I, Romero MJ, Beltran MA, Flores-Bellver M et al. Magnetic resonance imaging structural alterations in brain of alcohol abusers and its association with impulsivity. Addict Biol 2016; 21: 962-971.

2 Chanraud S, Martelli C, Delain F, Kostogianni N, Douaud G, Aubin H-J et al. Brain Morphometry and Cognitive Performance in Detoxified Alcohol-Dependents with Preserved Psychosocial Functioning. Neuropsychopharmacology 2007; 32: 429-438.

3 Chumin EJ, Goñi J, Halcomb ME, Durazzo TC, Dzemidzic M, Yoder KK. Differences in White Matter Microstructure and Connectivity in Nontreatment-Seeking Individuals with Alcohol Use Disorder. Alcohol Clin Exp Res 2018; 42: 889-896.

4 Crespi C, Galandra C, Manera M, Basso G, Poggi P, Canessa N. Executive Impairment in Alcohol Use Disorder Reflects Structural Changes in Large-Scale Brain Networks: A Joint Independent Component Analysis on Gray-Matter and White-Matter Features. Front Psychol 2019; 10. doi:10.3389/fpsyg.2019.02479.

5 Demirakca T, Ende G, Kämmerer N, Welzel-Marquez H, Hermann D, Heinz A et al. Effects of Alcoholism and Continued Abstinence on Brain Volumes in Both Genders. Alcohol Clin Exp Res 2011; 35: 1678-1685.

6 De Santis S, Bach P, Pérez-Cervera L, Cosa-Linan A, Weil G, Vollstädt-Klein S et al. Microstructural White Matter Alterations in Men With Alcohol Use Disorder and Rats With Excessive Alcohol Consumption During Early Abstinence. JAMA Psychiatry 2019; 76: 749-758.

7 Harris GJ, Jaffin SK, Hodge SM, Kennedy D, Caviness VS, Marinkovic K et al. Frontal White Matter and Cingulum Diffusion Tensor Imaging Deficits in Alcoholism. Alcohol Clin Exp Res 2008; 32 1001-1013.

8 Jang D-P, Namkoong K, Kim J-J, Park S, Kim I-Y, Kim Sl et al. The relationship between brain morphometry and neuropsychological performance in alcohol dependence. Neurosci Lett 2007; 428: 21-26.

9 Konrad A, Vucurevic G, Lorscheider M, Bernow N, Thümmel M, Chai C et al. Broad Disruption of Brain White Matter Microstructure and Relationship with Neuropsychological Performance in Male Patients with Severe Alcohol Dependence. Alcohol Alcohol 2012; 47: 118-126.

10 Mechtcheriakov S, Brenneis C, Egger K, Koppelstaetter F, Schocke M, Marksteiner J. A widespread distinct pattern of cerebral atrophy in patients with alcohol addiction revealed by voxelbased morphometry. J Neurol Neurosurg Psychiatry 2007; 78: 610-614.

11 Monnig MA, Caprihan A, Yeo RA, Gasparovic C, Ruhl DA, Lysne P et al. Diffusion Tensor Imaging of White Matter Networks in Individuals with Current and Remitted Alcohol Use Disorders and Comorbid Conditions. Psychol Addict Behav J Soc Psychol Addict Behav 2013; 27: 455-465.

12 Pandey AK, Ardekani BA, Kamarajan C, Zhang J, Chorlian DB, Byrne KN-H et al. Lower Prefrontal and Hippocampal Volume and Diffusion Tensor Imaging Differences Reflect Structural and Functional Abnormalities in Abstinent Individuals with Alcohol Use Disorder. Alcohol Clin Exp Res 2018; 42: 1883-1896.

13 Pitel A-L, Chételat G, Berre APL, Desgranges B, Eustache F, Beaunieux H. Macrostructural abnormalities in Korsakoff syndrome compared with uncomplicated alcoholism. Neurology 2012; 78: 1330-1333.

14 Sawyer KS, Maleki N, Papadimitriou G, Makris N, Oscar-Berman M, Harris GJ. Cerebral white matter sex dimorphism in alcoholism: a diffusion tensor imaging study. Neuropsychopharmacology 2018; 43: 1876-1883.

15 Segobin SH, Chételat G, Le Berre A-P, Lannuzel C, Boudehent C, Vabret F et al. Relationship between brain volumetric changes and interim drinking at six months in alcohol-dependent patients. Alcohol Clin Exp Res 2014; 38: 739-748.

16 Segobin S, Ritz L, Lannuzel C, Boudehent C, Vabret F, Eustache F et al. Integrity of white matter microstructure in alcoholics with and without Korsakoff's syndrome. Hum Brain Mapp 2015; 36: 2795-2808.

17 Yeh P-H, Simpson K, Durazzo TC, Gazdzinski S, Meyerhoff DJ. Tract-Based Spatial Statistics (TBSS) of diffusion tensor imaging data in alcohol dependence: abnormalities of the motivational neurocircuitry. Psychiatry Res 2009; 173: 22-30.

18 Zorlu N, Gelal F, Kuserli A, Cenik E, Durmaz E, Saricicek A et al. Abnormal white matter integrity and decision-making deficits in alcohol dependence. Psychiatry Res 2013; 214: 382-388. 
Table S3

Summarized information on measures and contrasts regarding the contributing studies to ALE clusters of convergence.

\begin{tabular}{|c|c|c|c|c|}
\hline ALE Cluster & $\begin{array}{c}\text { Contributing } \\
\text { experiments }(14 / 18)\end{array}$ & $\begin{array}{c}\text { No. of contributing } \\
\text { Foci }\end{array}$ & WM Measure & Contrast \\
\hline \multirow[t]{7}{*}{$\mathrm{C} 1$} & $\begin{array}{l}\text { Chanraud et al. (2007) } \\
\text { Crespi et al. (2019) }\end{array}$ & $\begin{array}{c}1 \\
13\end{array}$ & $\begin{array}{c}\text { Volume } \\
\text { FA } \\
\text { RD } \\
\text { AD } \\
\text { MD }\end{array}$ & $\begin{array}{c}\text { AUD }<\mathrm{HC} \\
\text { n. a. }{ }^{*}\end{array}$ \\
\hline & De Santis et al. (2019) & 1 & MD & $A U D>H C$ \\
\hline & Jang et al. (2007) & 1 & Density & $\mathrm{AUD}<\mathrm{HC}$ \\
\hline & Monnig et al. (2013) & 1 & FA & $\mathrm{AUD}<\mathrm{HC}$ \\
\hline & Pandey et al. (2018) & 1 & FA & $\mathrm{AUD}>\mathrm{HC}$ \\
\hline & Pitel et al. (2012) & 2 & Volume & $\mathrm{AUD}<\mathrm{HC}$ \\
\hline & Segobin et al. (2015) & 1 & FA & $\mathrm{AUD}<\mathrm{HC}$ \\
\hline \multirow[t]{7}{*}{$\mathrm{C} 2$} & Chumin et a. (2018) & 2 & FA & $\mathrm{AUD}<\mathrm{HC}$ \\
\hline & Crespi et al. (2019) & 3 & FA & n. a. ${ }^{*}$ \\
\hline & Demirakca et al. (2011) & 1 & Volume & $\mathrm{AUD}<\mathrm{HC}$ \\
\hline & De Santis et al. (2019) & 1 & $\mathrm{FA}$ & $\mathrm{AUD}<\mathrm{HC}$ \\
\hline & Konrad et al. (2012) & 1 & FA & $\mathrm{AUD}<\mathrm{HC}$ \\
\hline & Pandey et al. (2018) & 1 & $\begin{array}{l}\mathrm{FA} \\
\mathrm{RD}\end{array}$ & $\begin{array}{l}\text { AUD }<\mathrm{HC} \\
\text { AUD }>\mathrm{HC}\end{array}$ \\
\hline & Yeh et al. (2009) & 2 & $\begin{array}{l}\mathrm{RD} \\
\mathrm{MD}\end{array}$ & $\begin{array}{l}\text { AUD }>\mathrm{HC} \\
\text { AUD }>\mathrm{HC}\end{array}$ \\
\hline \multirow[t]{5}{*}{ C3 } & Asensio et al. (2016) & 1 & Volume & $\mathrm{AUD}>\mathrm{HC}$ \\
\hline & Crespi et al. (2019) & 3 & $\begin{array}{l}F A \\
A D \\
M D\end{array}$ & n. a. ${ }^{*}$ \\
\hline & Demirakca et al. (2011) & 1 & Volume & $\mathrm{AUD}<\mathrm{HC}$ \\
\hline & Pitel et al. (2012) & 1 & Volume & $\mathrm{AUD}<\mathrm{HC}$ \\
\hline & Segobin et al. (2015) & 1 & FA & $\mathrm{AUD}<\mathrm{HC}$ \\
\hline \multirow[t]{7}{*}{$\mathrm{C} 4$} & Crespi et al. (2019) & 6 & $\begin{array}{l}\mathrm{RD} \\
\mathrm{AD} \\
\mathrm{MD}\end{array}$ & n. a. ${ }^{*}$ \\
\hline & Demirakca et al. (2011) & 1 & Volume & $\mathrm{AUD}<\mathrm{HC}$ \\
\hline & $\begin{array}{l}\text { Segobin et al. (2015) } \\
\text { Zorlu et al. (2013) }\end{array}$ & $\begin{array}{l}2 \\
1\end{array}$ & $\begin{array}{l}\text { FA } \\
\text { FA } \\
\text { RD }\end{array}$ & $\begin{array}{l}\text { AUD }<\mathrm{HC} \\
\text { AUD }<\mathrm{HC} \\
\text { AUD }>\mathrm{HC}\end{array}$ \\
\hline & Not contributing (4/18) & & & \\
\hline & Harris et al. (2008) & & & \\
\hline & $\begin{array}{l}\text { Mechtcheriakov et al. } \\
(2007) \\
\text { Sawyer et al. (2018) }\end{array}$ & & & \\
\hline & Segobin et al. (2014) & & & \\
\hline
\end{tabular}

$\mathrm{FA}=$ fractional anisotropy, $\mathrm{RD}=$ radial diffusivity, $\mathrm{AD}=$ axial diffusivity, $\mathrm{MD}=$ mean diffusivity, $\mathrm{n} . \mathrm{a}^{*}=$ information not available, combined contrasts within joined independent component analysis. 


\section{Table S4}

Exploratory subgroup analysis of DTI studies investigating WM differences in AUD: ALE clusters significant after cluster-level FWE correction for multiple comparisons.

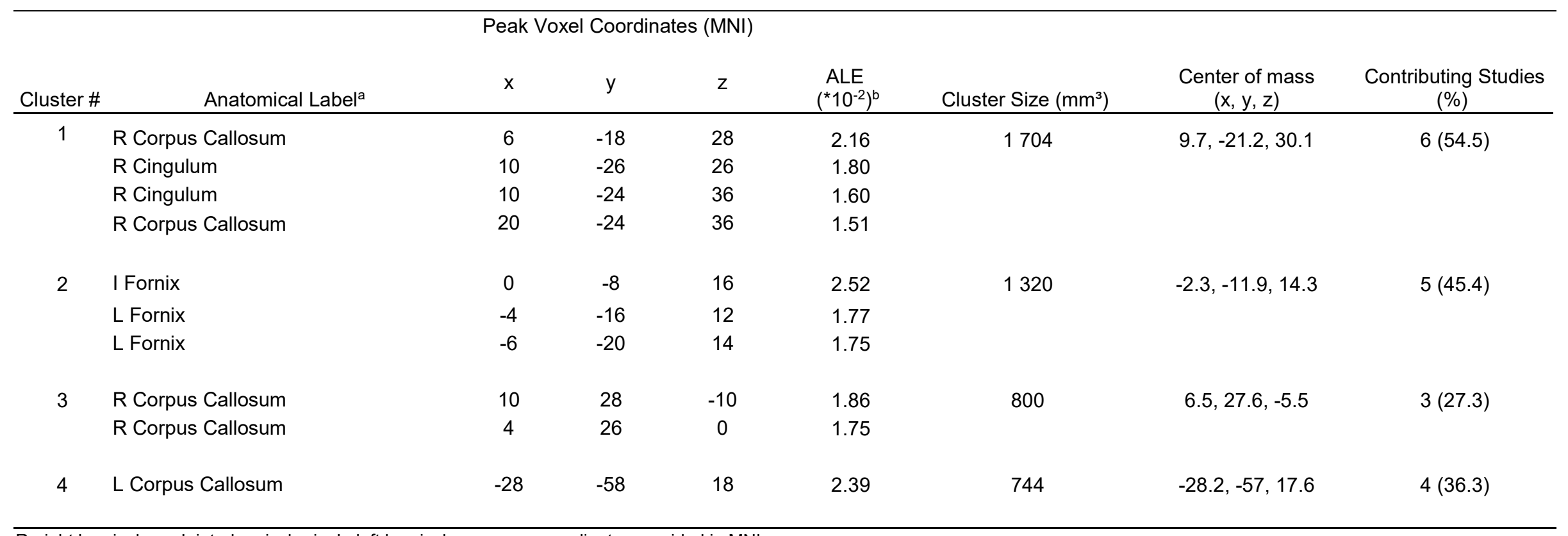

$\mathrm{R}$, right hemisphere; I, interhemispheric; L, left hemisphere; $\mathrm{x}, \mathrm{y}, \mathrm{z}$ coordinates provided in MNI space.

a Anatomical labelling according to the tractography based atlas of human brain connections (Catani et al., 2008), as implemented in MRIcroGL (v1.2.20210317, https://mww.mccauslandcenter.sc.edu/mricrogl). b Maximum ALE value observed in the cluster. 


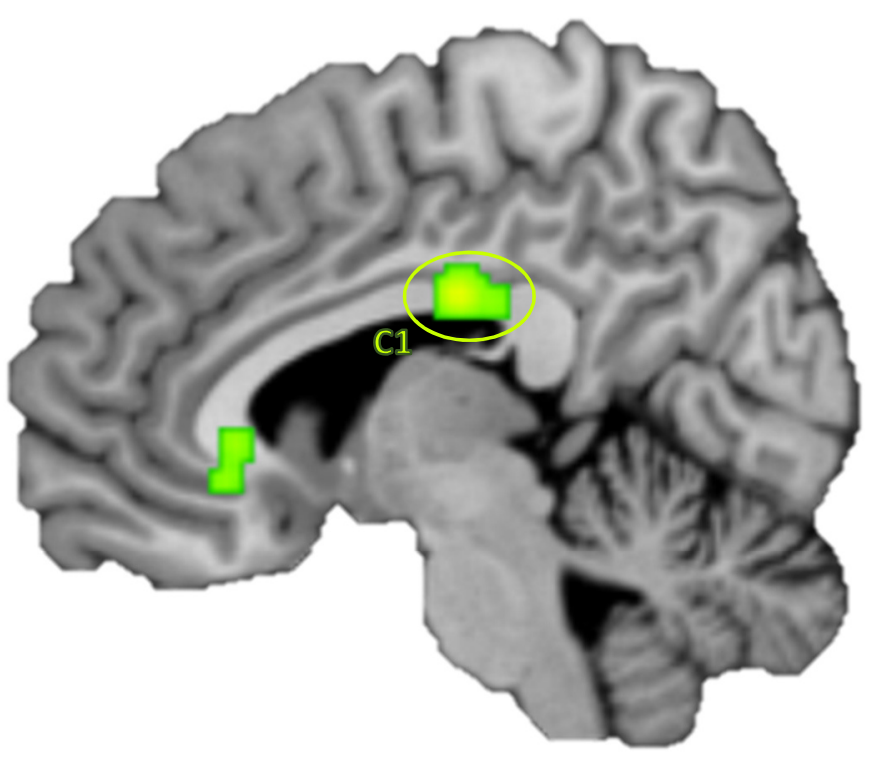

$x=6$

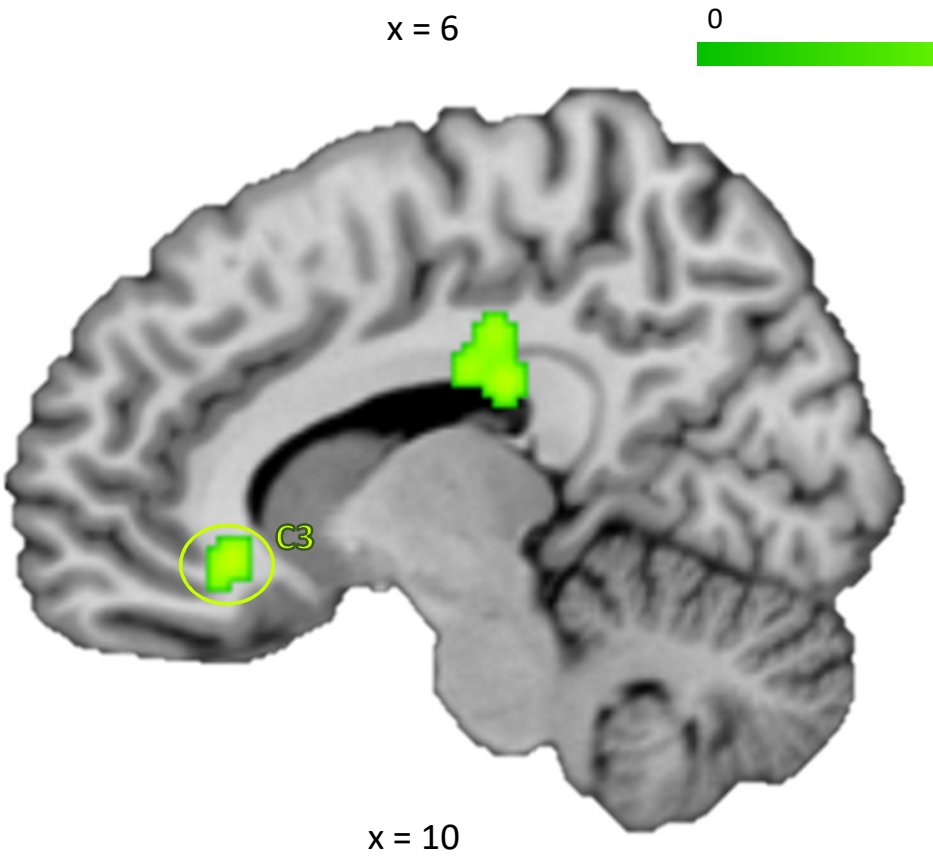

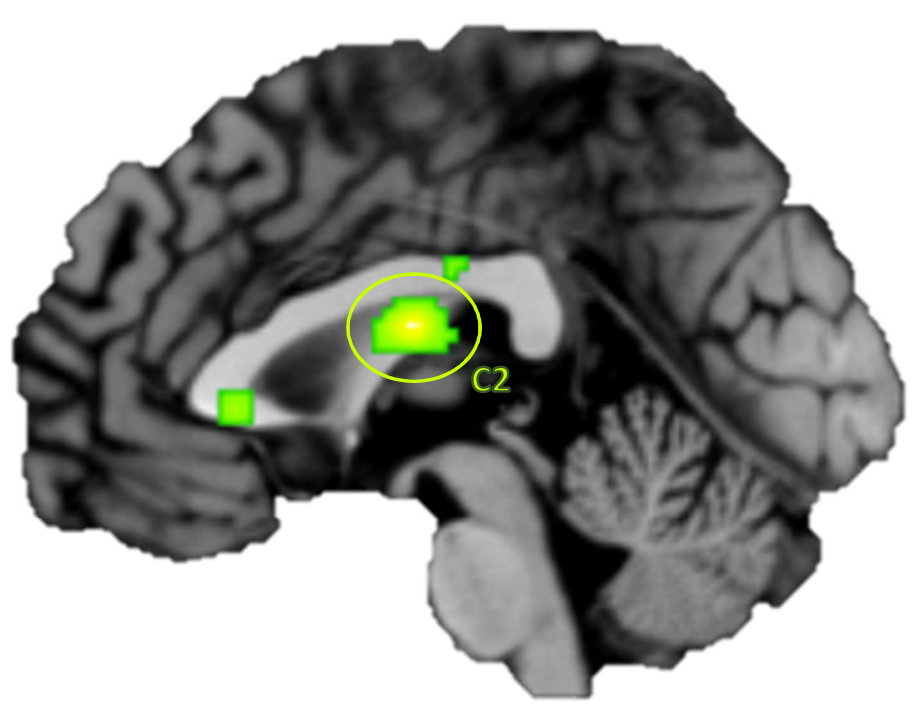

ALE

$x=0$

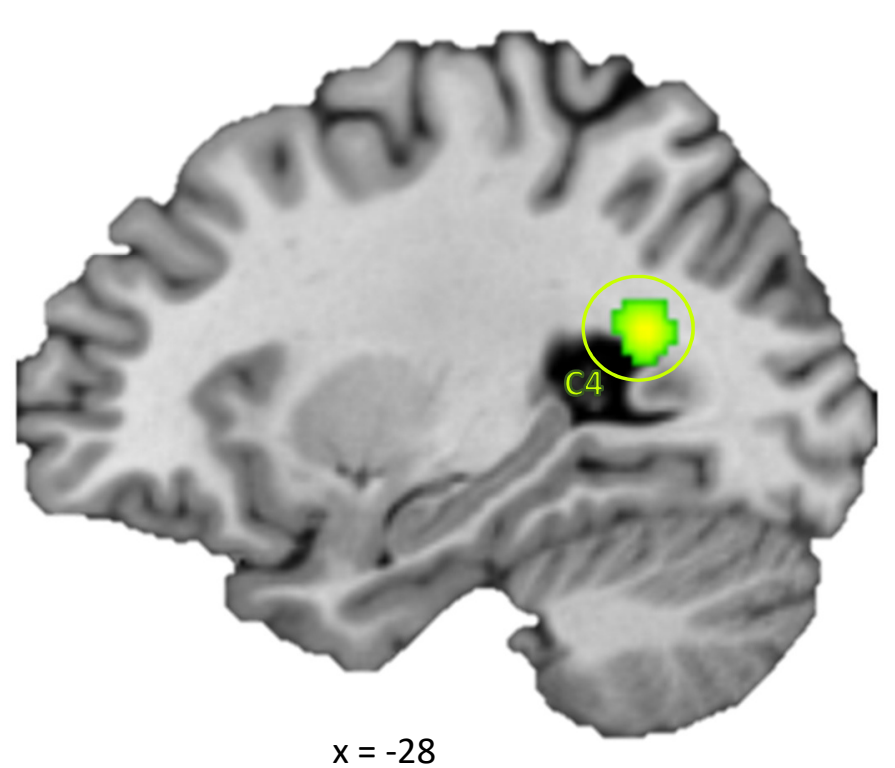

Fig. S1: Exploratory ALE subgroup analysis of DTI studies $(n=11)$ investigating WM differences in AUD. The highlighted clusters (C1-C4) represent significant convergence about microstructural white matter alterations in AUD patients compared to healthy controls. Clusters are depicted on brain slices of an MNI standard brain. Color indicates ALE value. Cluster-forming threshold $p<0.001$, family wise error (FWE) cluster level corrected at $p<0.05 . \mathrm{x}, \mathrm{y}$ and $\mathrm{z}$ values refer to coordinates in MNI space, for detailed MNI peak voxel coordinates of the ALE clusters see table S4. This image was created with Mango (v4.1., http://ric.uthscsa.edu/mango/). 


\section{Table S5}

Checklist for neuroimaging meta-analysis according to Müller et al. (2018).

\begin{tabular}{|c|c|}
\hline The research question is specifically defined & $\begin{array}{l}\text { YES, and it includes the following contrast: } \\
\text { whole brain macro- and microstructural WM } \\
\text { alterations in AUD vs. whole brain macro- and } \\
\text { microstructural WM alterations in HCs } \\
\rightarrow \text { Introduction, last paragraph }\end{array}$ \\
\hline The literature search was systematic & $\begin{array}{l}\text { YES, it included the following keywords in the } \\
\text { following databases: } \\
\text { Keywords: } \\
\text { (alcohol misuse OR alcoholism OR alcohol drinking } \\
\text { OR drinking behavior OR binge drinking OR } \\
\text { alcoholics OR alcohol use disorder OR alcohol } \\
\text { dependence OR alcohol addiction OR chronic } \\
\text { alcoholic intoxication OR alcohol abuse) } \\
\text { AND (white matter OR white brain matter OR } \\
\text { cerebellar white matter OR white matter integrity) } \\
\text { AND (diffusion tensor* OR DTI OR magnetic } \\
\text { resonance imaging OR tractography OR mean } \\
\text { diffusivity OR axial diffusivity OR radial diffusivity } \\
\text { OR fractional anisotropy OR structural connectivity } \\
\text { OR structural changes OR structural MRI OR voxel- } \\
\text { based morphometry OR VBM) } \\
\text { Databases: PubMed and EBSCO hosted PsycINFO, } \\
\text { PsycARTICLES, MEDLINE Complete, CINAHL } \\
\text { Complete and Psychology and Behavioral Sciences } \\
\text { Collection databases (up to January 18, 2021) } \\
\rightarrow \text { Methods section: Literature Search, Study } \\
\text { Selection and Data Extraction }\end{array}$ \\
\hline $\begin{array}{l}\text { Detailed inclusion an exclusion criteria are } \\
\text { included }\end{array}$ & $\begin{array}{l}\text { YES, and reasons of non-standard criterion were: } \\
\text { Exclusion of studies reporting null-findings, they } \\
\text { cannot be taken into account because they do not } \\
\text { provide spatial coordinates, which are a } \\
\text { prerequisite for the coordinate-based meta- } \\
\text { analytical approach. } \\
\rightarrow \text { Methods section: Literature Search, Study } \\
\text { Selection and Data Extraction }\end{array}$ \\
\hline Sample overlap was taken into account & $\begin{array}{l}\text { NO sample overlap was identified within the } \\
\text { studies eligible for inclusion and therefore data } \\
\text { from each study was managed as independent } \\
\text { experiment in the analysis. }\end{array}$ \\
\hline
\end{tabular}




\begin{tabular}{|c|c|}
\hline & $\begin{array}{l}\rightarrow \text { Methods section: Anatomical Likelihood } \\
\text { Estimation }\end{array}$ \\
\hline $\begin{array}{l}\text { All experiments use the same search } \\
\text { coverage (state how brain coverage is } \\
\text { assessed and how small volume corrections } \\
\text { and conjunctions are taken into account) }\end{array}$ & $\begin{array}{l}\text { YES, the search coverage is the following: } \\
\text { whole brain coverage only, verified via details of } \\
\text { the scanner parameters provided in the method } \\
\text { section of the papers and average brain sizes } \\
\text { provided by Müller et al. } 2018 \\
\rightarrow \text { Methods section: Literature Search, Study } \\
\text { Selection and Data Extraction }\end{array}$ \\
\hline $\begin{array}{l}\text { Studies are converted to a common } \\
\text { reference space }\end{array}$ & $\begin{array}{l}\text { YES, using the following conversion: } \\
\text { Coordinates reported in Talairach space were } \\
\text { transformed into MNI space using the Lancaster } \\
\text { transform icbm2tal implemented in GingerALE. } \\
\rightarrow \text { Methods section: Anatomical Likelihood } \\
\text { Estimation }\end{array}$ \\
\hline $\begin{array}{l}\text { Data extraction have been conducted by two } \\
\text { investigators (ideal case) or double checked } \\
\text { by the same investigator (state how double- } \\
\text { checking was performed) }\end{array}$ & $\begin{array}{l}\text { YES, the following authors: } \\
\text { Study selection: CS and LM (independently) } \\
\text { Disagreements: Solved by consensus with MM } \\
\text { Data extraction: CS and LM (independently) } \\
\text { Disagreements: Solved by consensus with MM } \\
\rightarrow \text { Methods section: Literature Search, Study } \\
\text { Selection and Data Extraction }\end{array}$ \\
\hline $\begin{array}{l}\text { The paper includes a table with at least the } \\
\text { references, basic study description (e. g. for } \\
\text { fMRI tasks: stimuli), contrasts and basic } \\
\text { sample descriptions (e.g. size, mean age and } \\
\text { gender distribution, specific characteristics) } \\
\text { of the included studies, source of } \\
\text { information (e.g. contact with authors), } \\
\text { reference space }\end{array}$ & $\begin{array}{l}\text { YES, and also the following data: } \\
\text { Additional clinical sample characteristics: } \\
\text { Diagnosis and Duration, Abstinence Duration } \\
\text { MRI: method, field strength, gradient directions } \\
\text { Pre-processing: Smooth Kernel, Software } \\
\text { Analysis: Method and threshold of correcting for } \\
\text { multiple comparisons, WM Measure, Covariates, } \\
\text { Results: contrasts, no. Foci, Reference Space, } \\
\text { Source of coordinates } \\
\rightarrow \text { Table } 1 \text { and table } \mathbf{S 2}\end{array}$ \\
\hline $\begin{array}{l}\text { The study protocol was previously registered } \\
\text { and all analyses planned beforehand, } \\
\text { including the methods and parameters used } \\
\text { for inference, correction for multiple testing, } \\
\text { etc. }\end{array}$ & $\begin{array}{l}\text { YES: } \\
\text { The meta-analysis was registered before starting } \\
\text { the search at: } \\
\text { PROSPERO (CRD42021231447) } \\
\rightarrow \text { Methods section }\end{array}$ \\
\hline
\end{tabular}


Table S5 continued

\begin{tabular}{|l|l|}
\hline The meta-analysis includes diagnostics & $\begin{array}{l}\text { YES, the following: } \\
\text { fail-safe N, name and number of contributing } \\
\text { experiments, measure, number of foci and } \\
\text { associated contrasts regarding the revealed ALE } \\
\text { clusters }\end{array}$ \\
$\rightarrow$ Table 2 and table S3
\end{tabular}




\begin{tabular}{|c|c|c|c|}
\hline Section and Topic & Item \# & Checklist item & $\begin{array}{l}\text { Location where } \\
\text { item is reported }\end{array}$ \\
\hline \multicolumn{4}{|l|}{$\begin{array}{l}\text { TITLE } \\
\end{array}$} \\
\hline Title & 1 & Identify the report as a systematic review (meta-analysis). & Cover \\
\hline \multicolumn{4}{|l|}{ ABSTRACT } \\
\hline Abstract & 2 & See the PRISMA 2020 for Abstracts checklist. & Abstract \\
\hline \multicolumn{4}{|l|}{ INTRODUCTION } \\
\hline Rationale & 3 & Describe the rationale for the review in the context of existing knowledge. & 1 Introduction \\
\hline Objectives & 4 & Provide an explicit statement of the objective(s) or question(s) the review addresses. & 1 Introduction \\
\hline \multicolumn{4}{|l|}{ METHODS } \\
\hline Eligibility criteria & 5 & Specify the inclusion and exclusion criteria for the review and how studies were grouped for the syntheses. & 2.1 Methods \\
\hline Information sources & 6 & $\begin{array}{l}\text { Specify all databases, registers, websites, organisations, reference lists and other sources searched or consulted to identify studies. Specify the date when } \\
\text { each source was last searched or consulted. }\end{array}$ & 2.1 Methods \\
\hline Search strategy & 7 & Present the full search strategies for all databases, registers and websites, including any filters and limits used. & 2.1 Methods \\
\hline Selection process & 8 & $\begin{array}{l}\text { Specify the methods used to decide whether a study met the inclusion criteria of the review, including how many reviewers screened each record and each } \\
\text { report retrieved, whether they worked independently, and if applicable, details of automation tools used in the process. }\end{array}$ & 2.1 Methods \\
\hline $\begin{array}{l}\text { Data collection } \\
\text { process }\end{array}$ & 9 & $\begin{array}{l}\text { Specify the methods used to collect data from reports, including how many reviewers collected data from each report, whether they worked independently, } \\
\text { any processes for obtaining or confirming data from study investigators, and if applicable, details of automation tools used in the process. }\end{array}$ & 2.1 Methods \\
\hline \multirow[t]{2}{*}{ Data items } & $10 a$ & $\begin{array}{l}\text { List and define all outcomes for which data were sought. Specify whether all results that were compatible with each outcome domain in each study were } \\
\text { sought (e.g. for all measures, time points, analyses), and if not, the methods used to decide which results to collect. }\end{array}$ & 2.1 Methods \\
\hline & $10 \mathrm{~b}$ & $\begin{array}{l}\text { List and define all other variables for which data were sought (e.g. participant and intervention characteristics, funding sources). Describe any assumptions } \\
\text { made about any missing or unclear information. }\end{array}$ & 2.1 Methods \\
\hline $\begin{array}{l}\text { Study risk of bias } \\
\text { assessment }\end{array}$ & 11 & $\begin{array}{l}\text { Specify the methods used to assess risk of bias in the included studies, including details of the tool(s) used, how many reviewers assessed each study and } \\
\text { whether they worked independently, and if applicable, details of automation tools used in the process. }\end{array}$ & 2.1 Methods \\
\hline Effect measures & 12 & Specify for each outcome the effect measure(s) (e.g. risk ratio, mean difference) used in the synthesis or presentation of results. & 2.1 Methods \\
\hline \multirow[t]{6}{*}{ Synthesis methods } & $13 a$ & $\begin{array}{l}\text { Describe the processes used to decide which studies were eligible for each synthesis (e.g. tabulating the study intervention characteristics and comparing } \\
\text { against the planned groups for each synthesis (item \#5)). }\end{array}$ & 2.1 Methods \\
\hline & $13 \mathrm{~b}$ & Describe any methods required to prepare the data for presentation or synthesis, such as handling of missing summary statistics, or data conversions. & 2.2 Methods \\
\hline & $13 \mathrm{c}$ & Describe any methods used to tabulate or visually display results of individual studies and syntheses. & 2.2 Methods \\
\hline & $13 d$ & $\begin{array}{l}\text { Describe any methods used to synthesize results and provide a rationale for the choice(s). If meta-analysis was performed, describe the model(s), } \\
\text { method(s) to identify the presence and extent of statistical heterogeneity, and software package(s) used. }\end{array}$ & 2.2 Methods \\
\hline & $13 \mathrm{e}$ & Describe any methods used to explore possible causes of heterogeneity among study results (e.g. subgroup analysis, meta-regression). & 2.2 Methods \\
\hline & $13 f$ & Describe any sensitivity analyses conducted to assess robustness of the synthesized results. & 2.1 Methods \\
\hline $\begin{array}{l}\text { Reporting bias } \\
\text { assessment }\end{array}$ & 14 & Describe any methods used to assess risk of bias due to missing results in a synthesis (arising from reporting biases). & 2.1 Methods \\
\hline $\begin{array}{l}\text { Certainty } \\
\text { assessment }\end{array}$ & 15 & Describe any methods used to assess certainty (or confidence) in the body of evidence for an outcome. & 2.1 Methods \\
\hline \multicolumn{4}{|l|}{ RESULTS } \\
\hline \multirow[t]{2}{*}{ Study selection } & $16 a$ & $\begin{array}{l}\text { Describe the results of the search and selection process, from the number of records identified in the search to the number of studies included in the } \\
\text { review, ideally using a flow diagram. }\end{array}$ & $\begin{array}{l}3.1 \text { Results \& } \\
\text { Figure } 1\end{array}$ \\
\hline & $16 \mathrm{~b}$ & Cite studies that might appear to meet the inclusion criteria, but which were excluded, and explain why they were excluded. & 3.1 Results \\
\hline $\begin{array}{l}\text { Study } \\
\text { characteristics }\end{array}$ & 17 & Cite each included study and present its characteristics. & $\begin{array}{l}\text { 3.1 Results \& } \\
\text { Table } 1 \text { \& Table S1 }\end{array}$ \\
\hline
\end{tabular}




\begin{tabular}{|c|c|c|c|}
\hline Section and Topic & Item \# & Checklist item & $\begin{array}{l}\text { Location where } \\
\text { item is reported }\end{array}$ \\
\hline $\begin{array}{l}\text { Risk of bias in } \\
\text { studies }\end{array}$ & 18 & Present assessments of risk of bias for each included study. & $\begin{array}{l}3.1 \text { Results \& } \\
\text { Table S2 }\end{array}$ \\
\hline $\begin{array}{l}\text { Results of individual } \\
\text { studies }\end{array}$ & 19 & $\begin{array}{l}\text { For all outcomes, present, for each study: (a) summary statistics for each group (where appropriate) and (b) an effect estimate and its precision (e.g. } \\
\text { confidence/credible interval), ideally using structured tables or plots. }\end{array}$ & $\begin{array}{l}3.1 \text { Results \& } \\
\text { Table S1 }\end{array}$ \\
\hline \multirow[t]{4}{*}{$\begin{array}{l}\text { Results of } \\
\text { syntheses }\end{array}$} & $20 \mathrm{a}$ & For each synthesis, briefly summarise the characteristics and risk of bias among contributing studies. & $\begin{array}{l}\text { 3.1 Results \& } \\
\text { Table } 1 \text { \& Table S1 } \\
\text { \& Table S2 }\end{array}$ \\
\hline & $20 \mathrm{~b}$ & $\begin{array}{l}\text { Present results of all statistical syntheses conducted. If meta-analysis was done, present for each the summary estimate and its precision (e.g. } \\
\text { confidence/credible interval) and measures of statistical heterogeneity. If comparing groups, describe the direction of the effect. }\end{array}$ & $\begin{array}{l}\text { 3.2 Results \& } \\
\text { Table } 2 \text { \& Table S3 }\end{array}$ \\
\hline & $20 \mathrm{c}$ & Present results of all investigations of possible causes of heterogeneity among study results. & $\begin{array}{l}3.4 \text { Results \& } \\
\text { Table S4 \& Fig. S1 }\end{array}$ \\
\hline & $20 \mathrm{~d}$ & Present results of all sensitivity analyses conducted to assess the robustness of the synthesized results. & 3.3 Results \\
\hline Reporting biases & 21 & Present assessments of risk of bias due to missing results (arising from reporting biases) for each synthesis assessed. & $\begin{array}{l}3.3 \text { Results \& } \\
\text { Table } 2\end{array}$ \\
\hline $\begin{array}{l}\text { Certainty of } \\
\text { evidence }\end{array}$ & 22 & Present assessments of certainty (or confidence) in the body of evidence for each outcome assessed. & $\begin{array}{l}3.2 \text { Results \& } \\
\text { Table } 2\end{array}$ \\
\hline \multicolumn{4}{|l|}{ DISCUSSION } \\
\hline \multirow[t]{4}{*}{ Discussion } & $23 a$ & Provide a general interpretation of the results in the context of other evidence. & 4 Discussion \\
\hline & $23 b$ & Discuss any limitations of the evidence included in the review. & 4 Discussion \\
\hline & $23 \mathrm{c}$ & Discuss any limitations of the review processes used. & 4 Discussion \\
\hline & $23 d$ & Discuss implications of the results for practice, policy, and future research. & 4 Discussion \\
\hline \multicolumn{4}{|c|}{ OTHER INFORMATION } \\
\hline \multirow{3}{*}{$\begin{array}{l}\text { Registration and } \\
\text { protocol }\end{array}$} & $24 a$ & Provide registration information for the review, including register name and registration number, or state that the review was not registered. & 2 Methods \\
\hline & $24 b$ & Indicate where the review protocol can be accessed, or state that a protocol was not prepared. & 2 Methods \\
\hline & $24 \mathrm{c}$ & Describe and explain any amendments to information provided at registration or in the protocol. & None \\
\hline Support & 25 & Describe sources of financial or non-financial support for the review, and the role of the funders or sponsors in the review. & $\begin{array}{l}\text { Acknowledgements } \\
\text { and Funding }\end{array}$ \\
\hline Competing interests & 26 & Declare any competing interests of review authors. & $\begin{array}{l}\text { Conflict of interest } \\
\text { statement }\end{array}$ \\
\hline $\begin{array}{l}\text { Availability of data, } \\
\text { code and other } \\
\text { materials }\end{array}$ & 27 & $\begin{array}{l}\text { Report which of the following are publicly available and where they can be found: template data collection forms; data extracted from included studies; data } \\
\text { used for all analyses; analytic code; any other materials used in the review. }\end{array}$ & $\begin{array}{l}\text { Open Access } \\
\text { Publication \& upon } \\
\text { request at } \\
\text { corresponding } \\
\text { Author }\end{array}$ \\
\hline
\end{tabular}


For more information, visit: http://www.prisma-statement.org/ 